\title{
Transcriptional organization, regulation and role of the Porphyromonas gingivalis W83 hmu haemin- uptake locus
}

\author{
Janina P. Lewis, ${ }^{1,2}$ Konrad Plata, ${ }^{1,3}$ Fan Yu, ${ }^{1}$ Adriana Rosato ${ }^{2}$ \\ and Cecilia Anaya ${ }^{1,4}$ \\ 1,2The Philips Institute ${ }^{1}$ and Department of Microbiology and Immunology ${ }^{2}$, Virginia \\ Commonwealth University, Richmond, VA, USA \\ ${ }^{3}$ Department of Molecular Biology, University of Gdansk, Gdansk, Poland \\ ${ }^{4}$ University of San Luis, San Luis, Argentina
}

Porphyromonas gingivalis, an oral bacterium associated with periodontal disease, requires haemin for growth. Although several multigenic clusters encoding haemin-uptake systems are present on the genome of $P$. gingivalis, little is known regarding their transcriptional organization and expression. This study identified a $23 \mathrm{kDa}$ iron-regulated haemin-binding protein encoded by a larger than previously reported variant of $h m u Y$. It was shown that the $h m u$ locus is larger than previously reported and is composed of six genes, hmUYRSTUV, encoding a novel hybrid haemin-uptake system. The locus has an operonic organization and the transcriptional start site is located 292 bp upstream of $h m u Y$. The data indicate that the regulation of the operon is iron-dependent. Interestingly, differential regulation within the operon was demonstrated, resulting in excess of the hmuYR message encoding the outer-membrane proteins when compared to the full-length transcript. In addition, the $h m u Y$ transcript is more prevalent than the $h m u R$ transcript. Secondary structure analysis of the hmUYRSTUV mRNA predicted the formation of several potential stem-loops in the $5^{\prime}$ ends of $h m u R$ - and $h m u S$-specific mRNAs, consistent with the differential regulation observed. Finally, it was demonstrated that haemin binding and uptake are elevated in iron-depleted conditions and are reduced $45 \%$ and $70 \%$, respectively, in an $h m u$-deficient strain when compared to the parental strain, indicating that the $h m u$ locus plays a major role in haemin acquisition in $P$. gingivalis. Since homologues of the $h m u$ locus were also found in Bacteroides fragilis, Bacteroides thetaiotaomicron and Prevotella intermedia, these findings may have implications for a better understanding of haemin acquisition in those organisms as well.

Received 19 March 2006

Revised 28 June 2006

Accepted 2 August 2006

\section{INTRODUCTION}

Bacterial virulence is dependent on the ability of microorganisms to acquire essential nutrients. One such nutrient is haemin. Haemin, an iron protoporphyrin IX, is an indispensable cofactor for proteins essential for metabolism and oxidative stress protection for most bacteria. Since some bacteria do not have the complete haemin biosynthetic pathway, they have to acquire the nutrient from the environment (Panek \& O'Brian, 2002; Rao et al., 1999; Schifferle et al., 1996). In addition, due to its abundance in the host, haemin serves as a valuable source of iron for most host-associated micro-organisms (Genco \& Dixon, 2001). Haemin is not freely available in the human host; it exists bound with host scavenging proteins, forming complexes

Abbreviations: DP, dipyridyl; OMV, outer-membrane vesicles; PPIX protoporphyrin IX; RACE, rapid amplification of cDNA ends.

Supplementary data are available with the online version of this paper. such as the haemoglobin-haptoglobin complexes (Hwang \& Greer, 1980), haemin-haemopexin complexes (Hrkal et al., 1974) and haemin-albumin complexes (Beaven et al., 1974). Therefore bacteria must be able to acquire the haemin from the host proteins either by proteolytic degradation and/or by expression of high-affinity binding receptors capable of wresting the haemin from the host haemin-binding proteins (Lee, 1995; Olczak et al., 2005). Since haemin is too large to freely diffuse through the bacterial membranes, bacteria have also developed mechanisms to transport the haemin across the membrane(s). Several reports show that the genes encoding the haemin-uptake systems are organized in operons (Ochsner et al., 2000; Stojiljkovic \& Hantke, 1994; Thompson et al., 1999; Vanderpool \& Armstrong, 2001; Wyckoff et al., 1998), indicating that such organization of these uptake systems is a common theme.

Arranging genes into operons might seem the perfect way to ensure regulation of all genes by a specific regulator as well as 
ensuring the expression of equal amounts of each protein. However, although most of the bacterial protein-dependent transport systems are encoded by genes organized in operons, the stoichiometry of the products of the operon is not always $1: 1: 1$. Differential expression within operons encoding various bacterial transport systems has been reported (Ehrmann et al., 1998; Khun et al., 2000; Ronpirin et al., 2001). This differential expression resulted in overexpression of promoter-proximal genes and was the result of either premature transcript termination or differential transcript stability. The importance of the stoichiometry of components involved in nutrient transport has been demonstrated by the Escherichia coli ferrichrome uptake system encoded by the $f h u A C D B$ operon (Mademidis \& Koster, 1998). The overexpression of the outer-membrane receptor, FhuA, led to increased uptake of ferric hydroxamates, but no improved uptake was observed when the inner-membrane transport components, FhuCDB, were overproduced. However, the stoichiometry of the components encoded by the fhuACDB operon as well as the mechanism to achieve the stoichiometry remain unknown. Also, despite the well-documented clustering of the genes of the haemin-uptake systems, not much is known regarding expression of the operons or possible differential expression of individual genes within each.

Porphyromonas gingivalis, a Gram-negative anaerobic bacterium, is implicated as a major aetiological agent in adult-onset periodontal disease (Slots et al., 1986). This disease is a chronic inflammatory condition of the supporting tissues of the teeth affecting $10-15 \%$ of adults (Fox, 1992). P. gingivalis lacks the complete protoporphyrin IX (PPIX) biosynthetic pathway and thus requires exogenous haemin for growth (Schifferle et al., 1996; Nelson et al., 2003). Three multigenic clusters encoding proteins thought to be involved in the haemin-acquisition pathway have been detected in the genome of $P$. gingivalis W83 (Nelson et al., 2003). The first locus, ihtABCDE, is composed of five ORFs encoding a TonB-dependent outer-membrane receptor (IhtA), lipoprotein (IhtB), periplasmic binding protein (IhtC), permease (IhtD) and cytoplasmic ATP-binding protein (IhtE) (Dashper et al., 2000). The second locus has a similar composition in that a TonB-dependent receptor Tla (also known as Tlr) is followed by a putative ATP-binding cassette haemin-transport system, htrABCD (Aduse-Opoku et al., 1997; Slakeski et al., 2000). Direct evidence for the role of the locus in haemin uptake was obtained using a Tladeficient mutant. This mutant was significantly impaired in its growth on low levels of haemin. Our studies focused on the third locus, hmu. A portion of the locus was first reported in P. gingivalis 53977 by Karunakaran et al. (1997). This group demonstrated the presence of a haeminrepressed gene encoding a TonB-dependent outer-membrane protein, HemR. Upstream of hemR, a 429 bp ORF (orf1) was located. The two genes were independently transcribed, and while hemR was repressed by haemin, orf1 was upregulated in the presence of haemin. Using a different $P$. gingivalis strain, A7436, Simpson et al. (2000) demonstrated the presence of a homologue of this locus consisting of $h m u Y$ (99\% identical to orfl) and hmuR (identical at the $5^{\prime}$ end to hemR but differing significantly at the $3^{\prime}$ end). hmuY and $h m u R$ are co-transcribed and repressed by iron. These potentially contradictory data provided valuable insight into the complexity of gene regulation within the locus. First, they demonstrated that genes within the locus were co-transcribed. However, the presence of multiple transcripts indicated that differential expression may take place within the locus. Ultimately they left the transcriptional organization and regulation of this system by iron and haemin in doubt.

The study reported here demonstrates that the $h m u Y$ variant in $P$. gingivalis W83 is much larger than the previously characterized variants and encodes a $23 \mathrm{kDa}$ iron-repressible outer-membrane protein. Furthermore, the genomic locus is also larger than previously reported and is composed of six genes, hmuYRSTUV, encoding proteins potentially involved in the haemin acquisition process. We determined the transcriptional organization and regulation of the hmuYRSTUV locus, and examined its role in haemin uptake.

\section{METHODS}

Bacterial strains, plasmids and media. Bacterial strains and plasmids used in this study are listed in Table 1. Porphyromonas gingivalis was maintained on blood agar plates (TSA II, $5 \%$ sheep blood; $\mathrm{BBL})$ in an anaerobic atmosphere composed of $80 \% \mathrm{~N}_{2}, 10 \% \mathrm{H}_{2}$, $10 \% \mathrm{CO}_{2}$, at $37^{\circ} \mathrm{C}$. Broth cultures of $P$. gingivalis were prepared using Brain Heart Infusion Broth (BHI) supplemented with haemin (5 $\mu \mathrm{g} \mathrm{ml}^{-1}$; Sigma) and menandione $\left(1 \mu \mathrm{g} \mathrm{ml}^{-1}\right.$; Sigma) (enriched BHI). Escherichia coli strain TOP10 (Invitrogen) was used as the host for plasmid manipulations and was maintained on LuriaBertani medium. Antibiotics (ampicillin, $100 \mu \mathrm{g} \mathrm{ml}^{-1}$, kanamycin, $50 \mu \mathrm{g} \mathrm{ml}^{-1}$ ) were used to select for E. coli transformants.

\section{Generation of iron-chelated conditions}

$P$. gingivalis stores large amounts of iron in the form of haemin at the cell surface. Also, the iron content of the BHI medium used to grow the bacteria is reported to be very high (approx. $1 \mathrm{mM}$ ) (Ahn et al., 2004; Rishi et al., 2004). To deplete iron from the culture medium and the bacterial cells, high concentrations of the ferrous iron chelator 2,2' dipyridyl (DP; Sigma) were used.

(i) For protein analysis. An actively growing culture was used to start two $10 \mathrm{ml}$ cultures in BHI supplemented with menandione (mBHI). One was grown in the presence of ferric chloride $(200 \mu \mathrm{M})$ (to create iron-replete conditions) and the other was supplemented with $150 \mu \mathrm{M}$ DP (to create iron-chelated conditions). Both cultures were incubated overnight. Cells were harvested and stored at $-80^{\circ} \mathrm{C}$. Supernatant was used to prepare extracellular vesicles as described previously (Lewis \& Macrina, 1998).

(ii) For RNA analysis. Two flasks of $200 \mathrm{ml} \mathrm{mBHI}$ were inoculated with $5 \mathrm{ml}$ of overnight culture. These cultures were grown until they reached mid-exponential phase $\left(\mathrm{OD}_{660} 0 \cdot 5\right)$. To one culture, ferric chloride $(200 \mu \mathrm{M})$ was added to generate iron-replete conditions; the other was supplemented with $150 \mu \mathrm{M}$ DP to create iron-chelated conditions. Cells were harvested after $1 \mathrm{~h}$ bacterial growth and stored at $-80^{\circ} \mathrm{C}$. 
Table 1. Strains and plasmids

\begin{tabular}{|c|c|c|}
\hline Strain/plasmid & Genotype/description & Source/reference ${ }^{\star}$ \\
\hline \multicolumn{3}{|l|}{ P. gingivalis } \\
\hline W83 & Wild-type & Lewis \& Macrina (1998) \\
\hline W12 & Wild-type & A. Progulske-Fox \\
\hline W50 & Wild-type & M. A. Curtis \\
\hline H66 & Wild-type & A. Progulske-Fox \\
\hline 381 & Wild-type & A. Progulske-Fox \\
\hline ATCC 53977 & Wild-type & H. Kuramitsu \\
\hline ATCC 33277 & Wild-type & H. Schenkein \\
\hline A7436 & Wild-type & H. Schenkein \\
\hline V2302 & Clinical isolate & H. Schenkein \\
\hline V2300 & Clinical isolate & H. Schenkein \\
\hline V2306 & Clinical isolate & H. Schenkein \\
\hline V2308 & Clinical isolate & H. Schenkein \\
\hline V2307 & Clinical isolate & H. Schenkein \\
\hline $\mathrm{T} 2$ & Clinical isolate & Forsyth Institute \\
\hline T5 & Clinical isolate & Forsyth Institute \\
\hline T6 & Clinical isolate & Forsyth Institute \\
\hline $\mathrm{T} 8$ & Clinical isolate & Forsyth Institute \\
\hline T9 & Clinical isolate & Forsyth Institute \\
\hline T11 & Clinical isolate & Forsyth Institute \\
\hline T12 & Clinical isolate & Forsyth Institute \\
\hline V2577 & Kgp-deficient derivative of W83 (kgp::ermF-ermAM) & Lewis et al. (1999) \\
\hline V2794 & HmuYRSTUV-deficient derivative of W83 (hmuY::ermF-ermAM) & This study \\
\hline \multicolumn{3}{|l|}{ E. coli } \\
\hline TOP10 & $\begin{array}{c}\mathrm{F}^{-} \text {mcrA } \Delta(\text { mrr-hsdRMS-mcrBC) } \phi 80 \text { lacZ } \Delta \mathrm{M} 15 \text { DlacX74 recA1 } \\
\text { ara139 } \Delta(\text { ara-leu }) 7697 \text { galU galK rpsL }\left(\mathrm{Str}^{\mathrm{R}}\right) \text { endA1 nupG }\end{array}$ & Invitrogen \\
\hline $\mathrm{DH} 5 \alpha$ & recA lacZYA-argF supE44 & Invitrogen \\
\hline BL21(DE3) & $\mathrm{F}^{-} o m p T h s d S_{\mathrm{B}}\left(\mathrm{r}_{\mathrm{B}}^{-} \mathrm{m}_{\mathrm{B}}^{-}\right) g a l d c m(\mathrm{DE} 3)$ & Invitrogen \\
\hline \multicolumn{3}{|l|}{ Plasmids } \\
\hline pET22b $+-h m u Y$ & pET22 containing 572 bp of $h m u Y$ cloned into NdeI-XhoI sites & This study \\
\hline pCRII-hmuR & pCRII vector containing $597 \mathrm{bp}$ of $h m u R$ & This study \\
\hline
\end{tabular}

${ }^{\star}$ A. Progulske-Fox, University of Florida, Gainesville, USA; M. A. Curtis, Queen Mary’s School of Medicine and Dentistry, London, UK; H. Kuramitsu, State University of New York, Buffalo, USA; H. Schenkein, Virginia Commonwealth University, Richmond, USA; Forsyth Institute, Boston, MA, USA.

\begin{abstract}
Preparation of bacterial cells for analysis of the effect of iron and haemin on expression of hmuYR. To determine the effect of various iron/haemin sources on expression of the $h m u$ locus we used medium that has low iron content $(1 \mu \mathrm{M})$ (Dashper et al., 2004). The remaining iron present in this medium was depleted by the addition of a low concentration of DP (final concentration $10 \mu \mathrm{M}) . P$. gingivalis cells were depleted of haemin by four serial passages in Mycoplasma broth (Becton Dickinson) supplemented with menandione. This culture was then used to inoculate Mycoplasma broth and Mycoplasma broth supplemented with bovine haemin $(1.5 \mu \mathrm{M})$, bovine haemoglobin $(1.5 \mu \mathrm{M})$, ferric chloride $(200 \mu \mathrm{M})$ and PPIX $(1.5 \mu \mathrm{M})$. DP was included in all samples at $10 \mu \mathrm{M}$ to chelate any free iron present in Mycoplasma broth. Samples were collected after $0,1,4$ and $24 \mathrm{~h}$ of growth. Bacterial cells were collected by centrifugation (12000 r.p.m., 2 min, $\left.4{ }^{\circ} \mathrm{C}\right)$ and stored at $-80^{\circ} \mathrm{C}$ prior to RNA isolation.
\end{abstract}

Cloning and purification of recombinant HmuY. We expressed a portion of the HmuY protein in E. coli using the T7 expression system (Novagen). We PCR-amplified a region (from bp 23 to bp
594) of the $h m u Y$ coding region using forward (23F) and reverse (23R) primers (see Supplementary Table S1, available with the online version of this paper). The PCR product was cloned into the pET22b expression vector (Novagen). The cloned fragment was rendered in-frame with six histidines encoded by the expression vector. This construct was introduced into E. coli BL21(DE3) cells and the expression of $h m u Y$ was induced with IPTG. Recombinant protein was purified on a nickel affinity column under denaturing conditions according to the manufacturer's instructions (Qiagen). Purity of this protein was assessed by SDS-PAGE (Laemmli, 1970). The remaining protein was dialysed against phosphate-buffered saline, $\mathrm{pH} 7 \cdot 3$, and stored at $-80^{\circ} \mathrm{C}$.

Haemin-binding assay of HmuY. Haemin binding to recombinant HmuY was examined using the peroxidase activity of haemoprotein (Francis \& Becker, 1984). Thus $10 \mu \mathrm{l}\left(0.5 \mathrm{mg} \mathrm{ml}^{-1}\right)$ recombinant $\mathrm{HmuY}$ was incubated with $1 \mu \mathrm{l}$ haemin solution $(10 \mathrm{mM})$ at room temperature for $10 \mathrm{~min}$. The LDS-PAGE gel containing the resolved protein was then washed twice for $30 \mathrm{~min}$ in TBS buffer $(10 \mathrm{mM}$ Tris/HCl, $\mathrm{pH} 7 \cdot 5,0.9 \% \mathrm{NaCl})$ and then 
developed with 4-methoxy-1-naphthol in the presence of $\mathrm{H}_{2} \mathrm{O}_{2}$. To detect total proteins present in the gel it was stained with Coomassie blue. BSA, demonstrated to bind haemin, was used as a positive control and trypsin was used as a negative control. Bovine haemoglobin served as a control for the haemin detection method.

Antibody production to recombinant HmuY. Polyclonal antibody to HmuY was generated in rabbits by Proteintech Group. Briefly, rabbits were immunized with $200 \mu \mathrm{g}$ of the HmuY recombinant protein in the presence of complete Freund's adjuvant. The animals were boosted twice at 14 day intervals with $100 \mu \mathrm{g}$ of the recombinant HmuY (mixed with Incomplete Freund's adjuvant) and 2 weeks later blood was collected. Sera were prepared and polyclonal HmuY antibody was affinity-purified using recombinant HmuY immobilized on a nitrocellulose membrane as described previously (Sexton et al., 2004) to remove background present when neat antiserum was used.

Western blot analysis. Proteins from various $P$. gingivalis cell fractions - whole-cell lysates, outer membranes (prepared as described by Dashper et al., 2000) and outer-membrane vesicles (OMV) (Lewis \& Macrina, 1998) - were solubilized in Laemmli buffer and separated by SDS-PAGE (Laemmli, 1970). The proteins were then transferred onto nitrocellulose membranes according to Towbin et al. (1992). The membrane was blocked for $40 \mathrm{~min}$ at room temperature in Tris-buffered saline (TBS) $+1 \%(\mathrm{w} / \mathrm{v})$ BSA, and incubated overnight in TBS containing affinity-purified antiHmuY serum at 1:500 dilution. After washing (three times, $10 \mathrm{~min}$ each) in TBS $+0.05 \%(\mathrm{v} / \mathrm{v})$ Tween 20 , the blot was incubated with a $1: 2000$ dilution of secondary antibody (anti-rabbit antibodies conjugated to horseradish peroxidase, Promega). After three washes, proteins were visualized with 4-chloro-1-naphthol in the presence of hydrogen peroxide.

Isolation of RNA. Total cellular RNA was isolated from P. gingivalis W83 cultures using an RNeasy mini kit according to the manufacturer's (Qiagen) instructions. Contaminating DNA was removed by treatment of the preparations with RNase-free DNase (Qiagen). For RT-PCR, any remaining DNA was removed by additional treatment with RNase-free DNase (Ambion) at $37^{\circ} \mathrm{C}$ for $1 \mathrm{~h}$. Total RNA preparations were stored at $-80^{\circ} \mathrm{C}$.

Northern blot hybridization. Eight micrograms of total RNA was electrophoretically separated and transferred to positively charged nylon membranes (Boehringer Mannheim) using commercially prepared buffers (Ambion). The integrity of the transferred RNA was assessed by visualization of the $16 \mathrm{~S}$ and $23 \mathrm{~S}$ RNA using UV light. Hybridizations were performed using specific probes labelled with peroxidase as instructed by the manufacturer (ECL kit; Amersham). Hybridizing bands were visualized using blue-light-sensitive film (Eastman Kodak).

Relative RT-PCR. Relative RT-PCR was performed in two steps. First, cDNA was synthesized with the SuperScript RNase $\mathrm{H}^{-}$reverse transcriptase (Invitrogen) and reverse gene-specific primers (Table S1) (50 pmol each) according to the manufacturer's instructions. Three hundred nanograms of RNA isolated from bacteria grown in iron-chelated conditions served as a template. The synthesis of cDNA was carried out for $60 \mathrm{~min}$ at $42{ }^{\circ} \mathrm{C}$. The synthesis of cDNA through regions containing predicted stem-loop structures ( $h m u Y R$ and $h m u R S$ ) was accomplished with thermostable reverse transcriptase (Thermoscript, Invitrogen) and higher temperature $\left(60^{\circ} \mathrm{C}\right)$. The cDNAs were then used for PCR amplifications with Platinum PCR Supermix HighFidelity mixtures (Invitrogen). Reactions were prepared according to the manufacturer's instructions with gene-specific primers. To determine the co-transcription within the $h m u$ locus, the following primer sets were used: 1619 and 263 (for $h m u Y R$ ), 267 and 265 (for $h m u R S$ ), 266 and 268 (for
hmuST), and 270 and 269 (for hmuTUV) (Fig. 3a, Table S1). The thermal profile consisted of: one cycle at $95^{\circ} \mathrm{C}$ for $3 \mathrm{~min}, 35$ cycles of $95^{\circ} \mathrm{C}$ for $45 \mathrm{~s}, 53{ }^{\circ} \mathrm{C}$ for $30 \mathrm{~s}$ and $72{ }^{\circ} \mathrm{C}$ for $2 \mathrm{~min}$, and an extension step of $72{ }^{\circ} \mathrm{C}$ for $7 \mathrm{~min}$. To demonstrate transcription and cotranscription within the hmuSTUV portion of the locus, two rounds of identical PCR were performed (using 1:10 dilution of the products from primary PCR as a template for the secondary PCR).

$5^{\prime}$ RACE. Amplification of the $h m u Y$ cDNA $5^{\prime}$ end was accomplished with the TaKaRa 5'-Full Race Core Set. Total RNA was isolated from $P$. gingivalis W83 using an RNeasy mini kit as described above (Qiagen). First-strand cDNA was synthesized using $200 \mathrm{pmol}$ $5^{\prime}$ phosphorylated primer (MSR) (Table S1) and $5 \mu$ g total RNA according to TaKaRa's $5^{\prime}$ RACE protocol. cDNA was purified with the MinElute PCR Purification kit (Qiagen) and self-ligated with T4 RNA ligase at $16^{\circ} \mathrm{C}$ for $18 \mathrm{~h}$.

Nested PCR was done to amplify the circularized single-stranded cDNA. The ligated cDNA was amplified by primary PCR using primers MSR2 and MSF7 (Table S1, Fig. 4c). Thermocycling conditions were as follows: preincubation at $94{ }^{\circ} \mathrm{C}$ for $5 \mathrm{~min}$, followed by 30 cycles of $94{ }^{\circ} \mathrm{C}$ for $30 \mathrm{~s}, 51{ }^{\circ} \mathrm{C}$ for $30 \mathrm{~s}$, and $72{ }^{\circ} \mathrm{C}$ for $30 \mathrm{~s}$, followed by an extension at $72{ }^{\circ} \mathrm{C}$ for $7 \mathrm{~min}$. Secondary PCR was done using primary PCR product diluted $1: 10$ as a template and primers MSR6 and MSF2 (Table S1, Fig. 4c). The thermocycling conditions were as described above. Presence of amplicons was determined using agarose gel electrophoresis. PCR products were extracted from gels using the Qiagen Gel Extraction kit and subjected to sequencing.

Construction of templates for generation of standard curves for quantitative PCR. DNA used as standard for quantification of real-time PCR products was made by PCR using primers listed in Table S1. Briefly, DNA templates approximately $500 \mathrm{bp}$ in length (except the $h m u V$-specific template, which was $350 \mathrm{bp}$ in length) were amplified using the following primer pairs: 26F and 26R (for $h m u Y$ ), MaxiF and MaxiR (for $h m u R$ ), 266 and USR (for $h m u S$ ), UTF and UTR (for $h m u T$ ), UUF and UUR (for $h m u U$ ), UVF and UVR (for $h m u V$ ) (see Table S1 for primer sequences and coordinates). Genomic DNA isolated from $P$. gingivalis W83 served as a template for generation of the PCR amplicons. The quality of PCR amplicons was assessed using agarose gel electrophoresis. Concentrations of DNA extracted from gels were determined by measuring $A_{260}$.

Real-time, quantitative RT-PCR. Quantitative TaqMan one step RT-PCR analysis was done with the TaqMan One Step PCR Master Mix Kit (Applied Biosystems). DNA-free total RNA isolated from bacterial cultures grown in iron-replete, iron-chelated and iron-limited conditions served as a template. Probes and primers (Table S1) were designed using Primer Express, version 2.0. The probes were labelled in the $5^{\prime}$ end with the fluorescent reporter FAM (6-carboxyfluorescein) and in the $3^{\prime}$ end with the fluorescent quencher TAMRA (6-carboxytetramethylrhodamine). Calibration curve plots for relative PCR were generated using serial fivefold dilutions of $0 \cdot 2 \mathrm{ng}$ genomic DNA and $100 \mathrm{ng}$ total RNA as templates. For transcript quantification, calibration curves for each gene of the $h m u$ locus were constructed using serial fivefold dilutions of $0.02 \mathrm{pg}$ gene-specific PCR products (prepared as described above). For quantification of $h m u Y$ - and $h m u R$-specific messages, serial fivefold dilutions of $0.02 \mathrm{ng}$ in vitro-synthesized $h m u Y$ and $h m u R$ transcripts were also used (information regarding the generation of the in vitrosynthesized RNA is available as supplementary data with the online version of this paper). The experimental samples were tested in triplicate under the conditions recommended by the manufacturer using $20 \mathrm{ng}$ total RNA (except for $16 \mathrm{~S}$ rRNA, where we used 0.02 ng total RNA). Reverse transcriptase was omitted in samples serving as negative controls. The experiments were performed in the ABI Prism 7900 Sequence Detection System (Applied Biosystems) 
with the thermal profile consisting of one cycle of $30 \mathrm{~min}$ at $48^{\circ} \mathrm{C}$ to synthesize cDNA; one cycle of $10 \mathrm{~min}$ at $95^{\circ} \mathrm{C}$; and 40 cycles each of $15 \mathrm{~s}$ at $95^{\circ} \mathrm{C}$ and $1 \mathrm{~min}$ at $60^{\circ} \mathrm{C}$. The threshold cycle was determined to provide the optimal standard curve values $(0.98$ to $1 \cdot 0)$. To control for the RNA quantity, a probe specific for $16 \mathrm{~S}$ rRNA was used.

Construction of a mutant strain. To construct an $h m u Y$ deletion mutant the entire ORF with its flanking sequences was PCR-amplified from W83 genomic DNA using 261 (forward) and 263 (reverse) primers (for primer positions and sequences see Table S1). The PCR product was subcloned into pCR2.1 (Invitrogen). A 437 bp ClaISspI fragment located between bp 127 and bp 618 of the $h m u Y$ gene was then replaced by the ermF-ermAM cassette (Fletcher et al., 1995). This recombinant plasmid was linearized with EcoRI, and electroporated into $P$. gingivalis W83. Double crossover between sequences flanking the resistance cassette and the wild-type gene rendered a mutant strain resistant to clindamycin. Southern blot analysis of clindamycin-resistant colonies was performed to determine the location of the ermF-ermAM cassette and to confirm the predicted structure of the allelic exchange product (results not shown). One mutant was selected for further analysis and was called V2794.

$\left[{ }^{55} \mathrm{Fe}\right]$ Haemin binding and uptake assay. Binding and uptake of $\left[{ }^{55} \mathrm{Fe}\right]$ haemin was evaluated in $P$. gingivalis strains grown in haemin/ iron-replete and haemin/iron-depleted conditions. Bacteria were depleted of haemin by serial passage in Mycoplasma broth. The haemin-depleted cells were inoculated into Mycoplasma broth supplemented with haemin and ferric chloride (iron-replete conditions) and in Mycoplasma broth containing $20 \mu \mathrm{M}$ DP (iron-depleted conditions) and grown to mid-exponential phase. For the uptake assay to ensure growth of bacteria the assay was performed in Mycoplasma broth (basal medium) serving as a source of nutrients and at $37^{\circ} \mathrm{C}$. Cells from overnight cultures were harvested and suspended to an $\mathrm{OD}_{660}$ of 0.6 in haemin-free basal medium. The MultiScreen assay system (Millipore) was used for the uptake experiments. The filtration 96-well plate was prewetted with $100 \mu \mathrm{l}$ basal medium, then $100 \mu \mathrm{l}\left(5 \times 10^{7}\right.$ cells $)$ of bacterial cells was added to selected wells. $\left[{ }^{55} \mathrm{Fe}\right] \mathrm{Haemin}$ [specific activity $0 \cdot 26 \mathrm{mCi} \mathrm{mg}^{-1}$ $\left(9 \cdot 6 \mathrm{MBq} \mathrm{mg}{ }^{-1}\right)$ ] was purchased from RI Consultants LLC. A stock solution $\left(0.5 \mathrm{mg} \mathrm{ml}^{-1}\right)$ was prepared in $0 \cdot 1 \mathrm{M} \mathrm{NaOH}$. Two working solutions, one containing only $\left[{ }^{55} \mathrm{Fe}\right]$ haemin $(100 \mu \mathrm{g}$ haemin $\mathrm{ml}^{-1}$ with specific activity $20 \mu \mathrm{Ci}[740 \mathrm{kBq}] \mathrm{ml}^{-1}$ ) and the other containing $\left[{ }^{55} \mathrm{Fe}\right]$ haemin $\left(50 \mu \mathrm{g} \mathrm{ml}^{-1}\right.$ with specific activity of $10 \mu \mathrm{Ci}$ $[370 \mathrm{kBq}] \mathrm{ml}^{-1}$ mixed with an equal amount of unlabelled haemin $\left(50 \mu \mathrm{g} \mathrm{ml}^{-1}\right)$, were prepared. Ten microlitres of the working solutions was added to designated wells and samples were incubated for $20 \mathrm{~min}$ at $37^{\circ} \mathrm{C}$, anaerobically. As control for energy-independent binding and uptake, the assay was also performed at $4{ }^{\circ} \mathrm{C}$. Liquid was then removed by vacuum, and cells were washed three times with $200 \mu \mathrm{l}$ TBS supplemented with $0 \cdot 1 \%(\mathrm{v} / \mathrm{v})$ Tween 20 (TBS-T). Filters were air-dried and collected in polyethylene scintillation vials (Fisherbrand; Fisher). Two millilitres of scintillation fluid was added to each vial and radioactivity was determined by scintillation counting with 'wide open' window setting, using a Beckman LS6500 scintillation counter. The active binding and uptake were determined by subtracting c.p.m. values obtained from experiments performed at $4{ }^{\circ} \mathrm{C}$ from those obtained at $37^{\circ} \mathrm{C}$.

Bioinformatics approaches. To determine the presence and stability of secondary structures within the mRNA we used the Mfold server as described by Zuker (2003) (http://www.bioinfo.rpi.edu/ applications/mfold/rna/forml.cgi).

Sequence similarity searches were done using the BLAST Program (NCBI, http://www.ncbi.nlm.nih.gov/). Comparison of the $P$. gingivalis $h m u$ locus to regions similar in other bacteria was done using the Comprehensive Microbial Resource available at The Institute for Genomic Research (http://www.tigr.org/).

\section{RESULTS}

\section{HmuY is the major protein upregulated in iron- depleted conditions}

We compared OMV protein profiles of $P$. gingivalis grown in BHI with and without DP. The OMV are derived from the outer membrane of the bacterium and their protein composition is also similar to that of the $P$. gingivalis outer membrane (Williams \& Holt, 1985). Since these vesicles are much easier to prepare compared with preparations of outer membranes, they were used in our initial studies. The SDS-PAGE analysis revealed drastic upregulation of a $23 \mathrm{kDa}$ protein (Fig. 1a). Several attempts to determine the $\mathrm{N}$-terminal sequence of this protein were unsuccessful. It was noteworthy that after incubation of the protein preparations at $37^{\circ} \mathrm{C}$ in reducing conditions the size of the protein band upregulated in iron-deficient conditions was reduced to $21 \mathrm{kDa}$ (data not shown). We determined the N-terminal sequence of the $21 \mathrm{kDa}$ protein. This sequence, DEPNQ, was used to search the $P$. gingivalis W83 translated sequence (Nelson et al., 2003; available at http://www.tigr.org/) using the tBLASTN program. This sequence matched a single ORF, potentially encoding a protein with an approximate size of $23 \mathrm{kDa}$ (Fig. 1c). This ORF was identical at its $3^{\prime}$ end to the previously reported HmuY protein, but contained 74 codons $5^{\prime}$ to the HmuY start codon, including an ATG start codon. Because the DEPNQ sequence was located upstream from the reported HmuY sequence, this suggests that the upstream ATG is the true start codon for HmuY.

The N-terminal sequence we obtained by sequencing the $21 \mathrm{kDa}$ derivative of the $23 \mathrm{kDa}$ protein indicates that $\mathrm{HmuY}$ undergoes proteolytic processing after the 25th amino acid residue. This is a lysine residue and it is possible that the proteolytic cleavage at this site was mediated by the lysine-specific protease Kgp (Curtis et al., 1999; Lewis et al., 1999). This hypothesis was verified by Western blot analysis of OMV derived from the parental strain (W83) and a Kgpdeficient strain (V2577) (Lewis \& Macrina, 1998) using anti$\mathrm{HmuY}$ antibody. For proteolytic processing of the proteins, the vesicles were incubated for $1 \mathrm{~h}$ at $37^{\circ} \mathrm{C}$ prior to gel electrophoresis. A $23 \mathrm{kDa}$ band was observed in vesicles from the Kgp-deficient strain while this band was missing in the vesicles from the parental strain; instead the parental strain displayed a $21 \mathrm{kDa}$ band (results not shown).

To confirm the identity of the $23 \mathrm{kDa}$ protein, its cellular location, and its upregulation in iron-depleted media, we performed Western blot analysis using affinity-purified polyclonal antisera raised against a recombinant form of the protein, constructed from the longer version of the $\mathrm{HmuY}$ ORF (Fig. 1b). A more intense $23 \mathrm{kDa}$ protein band was detected in the lane containing proteins derived from $P$. 

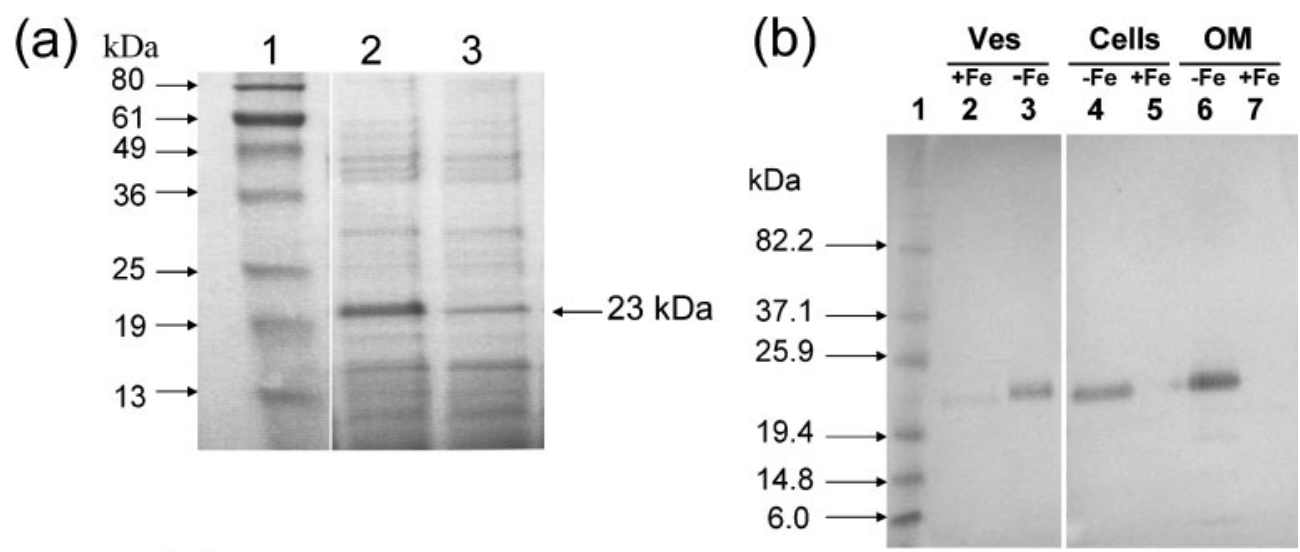

(c)

MKKIIFSALCALPLIVSLTSCGKKKDEPNQPSTPEAVTKTVTIDAS
KYETWQYFSFSKGEVVNVTDYKNDLNWDMALHRYDVRLNCG
ESGKGKGGAVFSGKTEMDQATTVPTDGYTVDVLGRITVKYEMG
PDGHQMEYEEQGFSEVITGKKNAQGFASGGWLEFSHGPAGPTY
KLSKRVFFVRGADGNIAKVQFTDYQDAELKKGVITFTYTYPVK

Fig. 1. Iron-dependent protein expression in P. gingivalis W83. (a) SDS-PAGE analysis. Fifteen micrograms of OMV derived from $P$. gingivalis W83 grown in iron-chelated (lane 2) and iron-replete (lane 3 ) conditions was resolved on the gel. The major upregulated protein in iron-depleted conditions is indicated by the arrow on the right. (b) Western blot analysis of $P$. gingivalis W83 proteins derived from $20 \mu \mathrm{g}$ OMV (lanes 2, 3), $60 \mu \mathrm{g}$ whole cells (lanes 4, 5), and $20 \mu \mathrm{g}$ outer-membrane preparations (lanes 6,7$)$ using anti-HmuY antibody. Proteins were derived from bacteria grown in $\mathrm{mBHI}$ in iron-chelated $(+150 \mu \mathrm{M} \mathrm{DP})$ (lanes 3, 4, 6) and iron-replete conditions (+ferric chloride) (lanes 2, 5, 7). (c) Predicted amino acid sequence of the $23 \mathrm{kDa}$ protein (HmuY). Amino acids identified by $\mathrm{N}$-terminal amino-acid sequencing of partially processed $\mathrm{HmuY}$ (21 kDa protein) are indicated in bold (DEPNQ). The underline indicates amino acids not found in previously published variants of the protein: ORF1 (Karunakaran et al., 1997) and HmuY (Simpson et al., 2000). The boxed sequence denotes the lipoprotein motif (VSLTSC).

gingivalis grown in iron-depleted conditions (Fig. 1b, lane 3) compared with the lane containing proteins from bacteria grown in iron-replete conditions (Fig. 1b, lane 2). This confirms that $\mathrm{HmuY}$ is the $23 \mathrm{kDa}$ iron-regulated protein seen in Fig. 1(a). Also, only one protein $23 \mathrm{kDa}$ in size was detected in $P$. gingivalis, which is in agreement with the size predicted from the HmuY protein sequence. Lastly, to confirm that HmuY is located in the outer membrane, we analysed protein preparations from outer membranes and compared them to those of whole-cell lysates and vesicles. An iron-repressed $23 \mathrm{kDa}$ protein was detected in vesicles, whole-cell lysates and outer membranes (Fig. 1b, lanes 2, 3, $4,5,6,7)$, thus further supporting the location of the protein in the outer membrane of $P$. gingivalis.

\section{Analysis of hmuYRSTUV indicates that it is a novel haemin-uptake locus}

Our study demonstrates that the HmuY protein is larger by the N-terminal 74 aa (Fig. 1c, underlined sequence) than its previously reported variants (Karunakaran et al., 1997; Simpson et al., 2000). Also, the originally described HmuY led to incorrect annotation of the $h m u Y$ gene on the genome of $P$. gingivalis W83 at both Oralgen (http://www.oralgen. lanl.gov) and TIGR (http://www.tigr.org). Further analyses revealed that the $\mathrm{N}$-terminus of the $23 \mathrm{kDa}$ protein (HmuY) contained the typical prokaryotic membrane lipoprotein attachment site: vsLTSC (aa 16-21; see Fig. 1c, Box 1). In addition, the $\mathrm{N}$-terminal sequence upstream of the lipoprotein motif is typical for a prokaryotic leader sequence; the positively charged N-terminus (Met followed by two Lys residues) is followed by a region of hydrophobic residues (typical for an intermembrane region). The acylation of the protein and presence of a leader sequence would be consistent with the outer-membrane location of $\mathrm{HmuY}$ and thus are further evidence that the original $\mathrm{HmuY}$ annotation was mistaken.

Analysis of the sequence surrounding $h m u Y R$ in the genome of $P$. gingivalis W83 revealed that there is another portion of the locus, which we designated hmuSTUV, that may have been missed in previous reports as being part of the same operon (Karunakaran et al., 1997; Simpson et al., 2000) (Fig. 2). These genes within this portion of the locus are separated by short intergenic regions which lack promoter signature sequences, consistent with the possibility that they are transcribed from a common promoter located upstream of $h m u Y$. The last gene of the putative operon, $h m u V$, is 


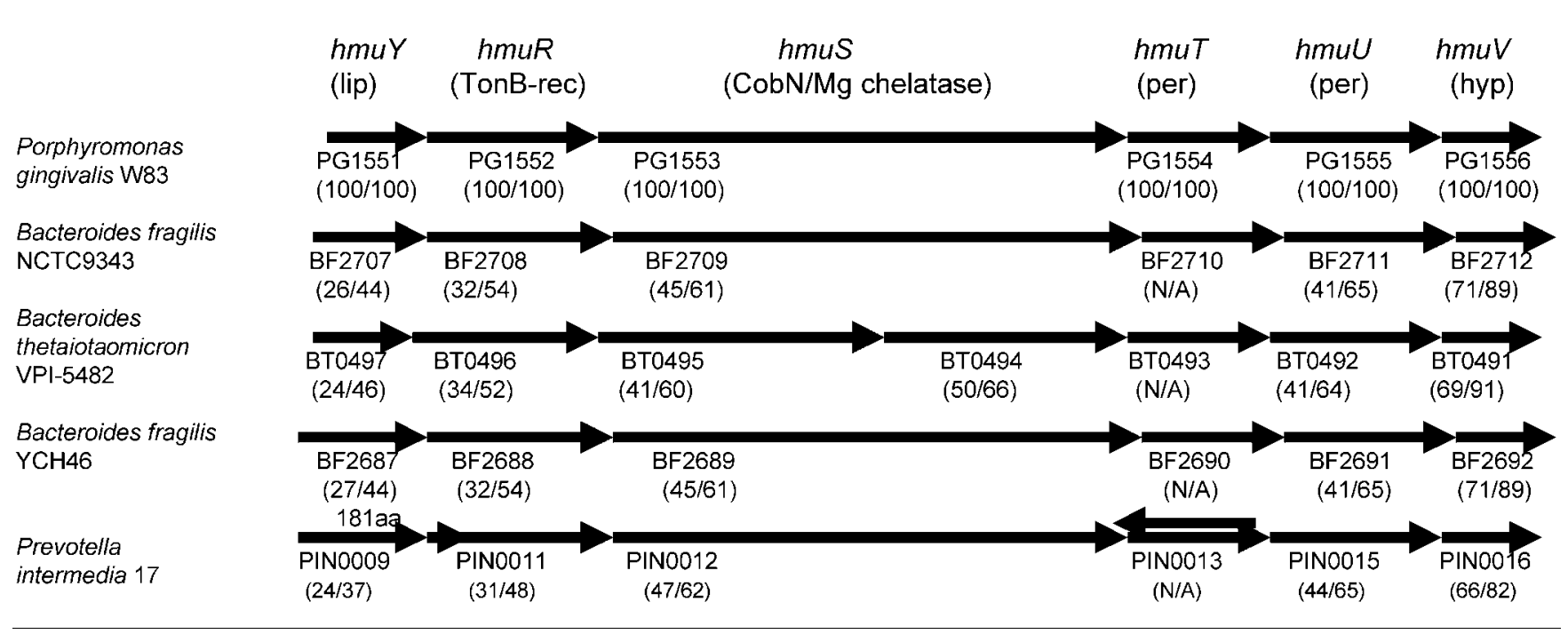

Fig. 2. Schematic representation of $h m u$ loci in bacteria. Genomic regions encoding proteins similar to the $P$. gingivalis $h m u$ locus were identified using the BLAST similarity searches. Our names for the $P$. gingivalis genes are included above the arrows. The predicted functions of the gene products are shown in parentheses: lip, lipoprotein; TonB-rec, TonB-dependent receptor; CobN/Mg chelatase, fusion protein of cobalamin and magnesium chelatase; per, permease; hyp, hypothetical protein. TIGR designations for the ORFs present in the analysed bacteria are used. The degree of identity and similarity of the putative proteins encoded by the ORFs to the corresponding proteins encoded by the $P$. gingivalis $h m u$ locus is indicated in parentheses (\% identity $\%$ similarity) and reflects the similarity over the entire lengths of the proteins. N/A, no significant similarity of the proteins encoded by the ORFs to HmuT was detected.

separated from its downstream gene by $937 \mathrm{bp}$. This gene, $g c v T$, encodes an aminomethyltransferase and is transcribed in the opposite orientation, indicating that it does not belong to the $h m u$ locus.

The hmuSTUV portion of the locus encodes a fusion of a putative cobalamin biosynthesis ( $\mathrm{CobN}) /$ magnesium chelatase (HmuS), two putative proteins containing multiple predicted transmembrane regions (typical for permeases) ( $\mathrm{HmuT}$ and $\mathrm{HmuU}$ ), and a putative protein containing an $\mathrm{N}$-terminal transmembrane region (suggesting that it is membrane associated). As Gram-negative bacterial irontransport systems typically are composed of an outermembrane receptor, a periplasmic binding protein, an inner-membrane transporter (permease) and an innermembrane-associated protein which can bind and hydrolyse ATP (Clarke, 2001), the structural composition of the proteins encoded by the $h m u$ locus is novel for a haeminuptake locus.

\section{Prevalence and regulation of the hmu locus}

To further assess the significance of our study we examined the presence of the locus in commonly used $P$. gingivalis laboratory strains and in various clinical isolates. Using PCR amplification with primers 261 ( -576 to -555 bp upstream of $h m u Y$ ) and 23R (594-573 bp of $h m u Y$ ), designed to amplify the $h m u Y$ gene with the upstream region, we detected the presence of the locus in the genomes of all but one (strain 381) of the P. gingivalis strains listed in Table 1.
These data indicate that the $h m u$ locus is very common among $P$. gingivalis strains. The $1.2 \mathrm{~kb}$ PCR products obtained using genomic DNA from the various strains as a template were sequenced and the sequences were aligned with that from $P$. gingivalis W83. Notably, the additional 1 bp present after bp 105 in the previously reported variant of $h m u Y$, orf1 (Karunakaran et al., 1997), was missing in all strains examined, in agreement with the sequence reported in this study (see Fig. S1, available as supplementary data with the online version of this paper). These data suggest that the longer version of $h m u \mathrm{Y}$ encoding a $23 \mathrm{kDa}$ protein described in our study is found in most $P$. gingivalis strains and that the previously reported shorter versions of the gene resulted from rare mutations or sequencing errors.

We also searched other bacterial genomes for the presence of a locus similar to $P$. gingivalis $h m u$. Interestingly, similar loci were found in other anaerobic bacteria: Bacteroides fragilis, Bacteroides thetaiotaomicron and Prevotella intermedia (Fig. 2). These loci encode proteins that exhibited significant identity and similarity through their entire lengths (with the exception of HmuT). Importantly, growth of these bacteria is also dependent on exogenously provided haemin and it is possible the $h m u$ locus plays a role in haemin acquisition in these bacteria as well. Our studies indicate that, similarly to the $P$. gingivalis $h m u$ locus, the Prevotella intermedia $h m u$ locus is also drastically upregulated in irondepleted conditions (data not shown), suggesting that a similar regulatory mechanism governs the gene expression within the loci. 
(a)

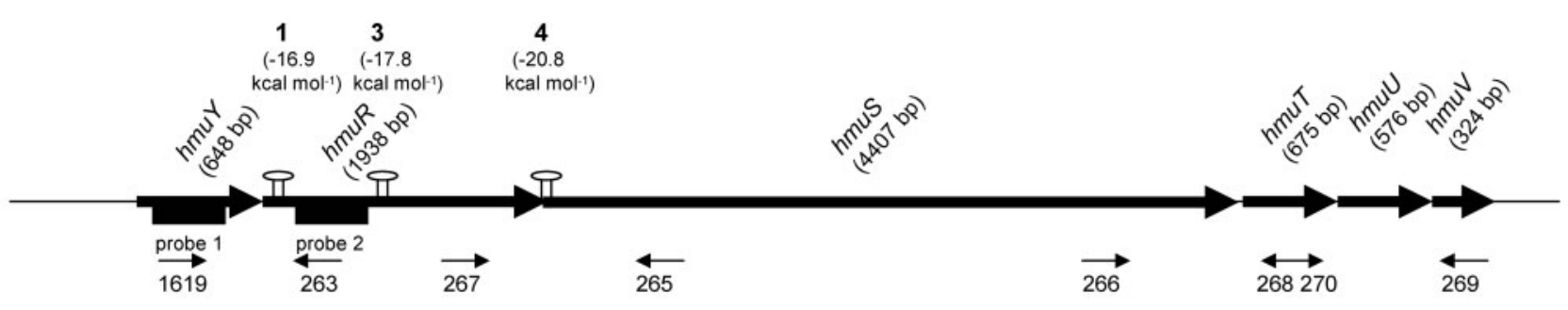

(b)

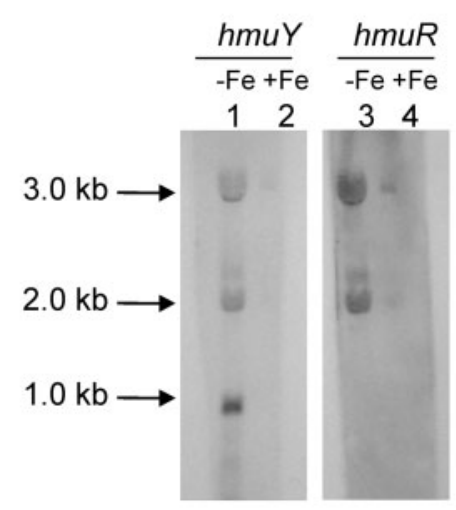

$1 \mathrm{~kb}$

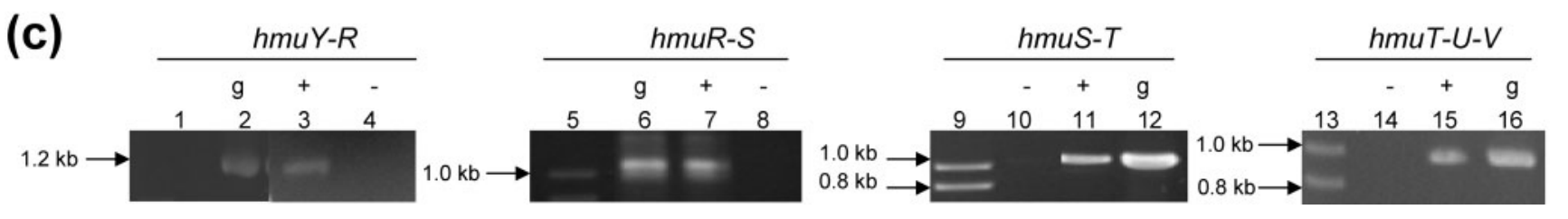

Fig. 3. Organization of the $P$. gingivalis W83 $h m u$ locus. (a) Schematic representation of the $h m u$ locus. Genes are depicted by arrows, and gene designations are shown above the arrows. Positions of sequences capable of forming secondary structures within the predicted mRNA are shown above the genes, and calculated energies of dissociation are included in parentheses $\left(\mathrm{kcal} \mathrm{mol}^{-1} ; 1 \mathrm{kcal}=4.184 \mathrm{~kJ}\right)$. Primers used in this study are indicated. Probes used for Northern blot analysis and their positions are depicted by black boxes (probe 1 and probe 2). (b) Northern blot analysis of total RNA isolated from $P$. gingivalis W83 grown in iron-chelated $(-\mathrm{Fe})$ and iron-replete $(+\mathrm{Fe})$ conditions. The blots were hybridized with peroxidaselabelled hmuY (probe 1) or hmuR (probe 2) PCR products. Transcripts and their sizes are indicated by arrows. The blots shown are examples of replicate experiments all showing similar transcript profiles. (c) Co-transcription within the $h m u$ locus. Lane designations: 'g', genomic DNA (lanes 2, 6, 12, 16), '+', cDNA (reverse transcriptase included, lanes 3, 7, 11, 15), '-', negative control (reverse transcriptase omitted, lanes 4, 8, 10, 14). The following primer pairs were used: 1619-263 (lanes 2 , 3, 4; hmuY-hmuR co-transcription), 267-265 (lanes 6, 7, 8; hmuR-hmuS co-transcription), 266-268 (lane 10, 11, 12; hmuShmuT co-transcription) and 270-269 (lanes 14, 15, 16; hmuT-U-V co-transcription). The sizes of standards in kb (lanes 1, 5, $9,13)$ are shown on the left.

The fact that most bacterial haemin-uptake encoding genes are organized in operons led us to study the possibility of the $h m u$ genes having an operonic organization as well. Furthermore, the previously reported putative regulatory sequences (Fur-binding sites; Karunakaran et al., 1997) are within the coding region of $h m u Y$ and as such may not play a role in regulation of the locus. Therefore the regulatory mechanism of the locus remains to be determined. To gain an insight into possible regulatory mechanisms, we examined the role of iron and haemin in regulation of the $h m u$ locus and determined the transcriptional start site. Then we examined the possibility of differential gene expression within the locus. Finally, we determined the role of the locus in haemin uptake and the biological significance of the of the iron regulation.

\section{Secondary structures may form within hmUYRSTUV MRNA}

Secondary structures may form within operons and contribute to differential gene expression within the operons by either impeding the transcription process or stabilizing the upstream mRNA (Newbury et al., 1987a). To investigate the possibility of differential gene expression within the $\mathrm{hmu}$ locus, we analysed the predicted mRNA for the presence of secondary structures, such as stem-loops. First, we analysed the intergenic sequences for the presence of secondary structures. No secondary structures were detected. Then, we analysed the coding regions of $h m u R$ and $h m u S$ for the presence of repeated sequences capable of forming secondary structures. Since local structures (formed within 
(a)

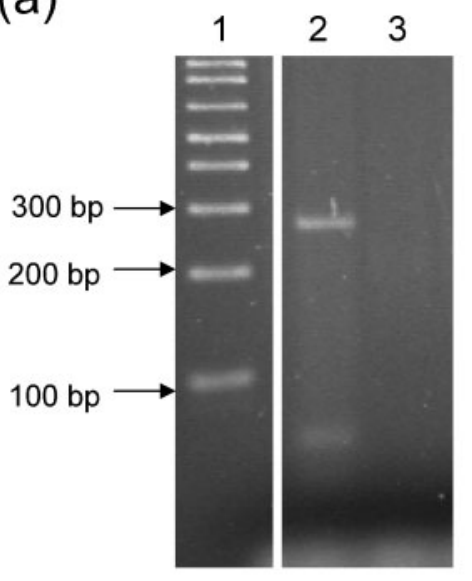

(b)

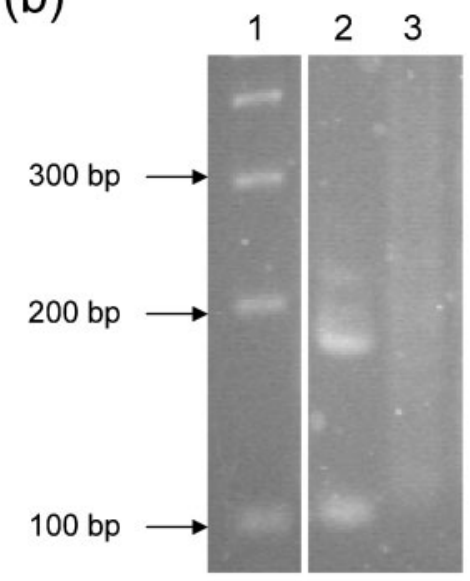

(c)

Sequence present upstream of $h m u Y$

AGTCATCCCCTAAAAGTCCCTITTAGGGAGATATTGTCAGCAAACAGTATCTCGCAGATTGTTTTGATAAAGTCCAAAAGAGCCTTCATAGCTCTCT

$\begin{array}{cccc}\text { TGAGTTCATAGGCTGCTGCCGCAAGAAGTATG TTCACGGTGTCCACTCTCATCCCTTTG TATAAGTTGCAACCTAAGCGATAACCTTCTCTTTTTCAA } & -10 \quad+1(-292 \text { bp })\end{array}$

AGgCCTCATTAGATGATTTTCCTTGTCGTGCCATAGCTTTGTGTCATTGATCATACCATAAACACACGGAATAATCGGCTGATACACAAATAATAAATG 3' CTAGTATGGTATTTGTGTGCCT 5' MSR6

AATAAAAGCACCTATGTATCGAGGGCTTTTTCATGTGCAATTCCAGTATTCCCAATACCACTTATTTAGTATAAATCCGACATTAAATACCTACAAATTG 3' GTACACGTTAAGGTCATAAGG 5' MSR2 5 ' CCTACAAATTG GGATTGCTCGTTTTTTGTGAACATCTCAACTTTGCAGCCGGATGAAACCTATTAAAAGTAAGGTCAGATAATTATGAAAAAAATCATTTTCTCCGCACTC GGATTGCTCG 3' MSF7 5'CATCTCAACTTTGCAGCCGG 3' MSF2 RBS Met 3' GAGGCGTGAG TGTGCATTGCCATTGATT ACACGTAAC 5' MSR-P

Fig. 4. Analysis of the $h m u Y$ promoter region. (a, b) RACE products: ethidium-bromide-stained agarose gel containing primary PCR obtained with primers MSR2 and MSF7 (a) and secondary PCR products obtained using primers MSR6 and MSF2 (b) to amplify ligated cDNA (lane 2) and ligated RNA (RT omitted during cDNA synthesis) (lane 3). (c) Sequence upstream of the $h m u$ operon. The translational start site (Met) and ribosome-binding site (RBS) are indicated. The sequences used to design primers are underlined; primer sequences and their $5^{\prime}$ and $3^{\prime}$ orientations are also shown. The 22 bp region upstream of the transcriptional start site capable of forming secondary structures is indicated by arrows.

relatively short sequences) are more likely to form in vivo we analysed the sequences progressively using $60 \mathrm{bp}$ regions. Notably, the $5^{\prime}$ region of the $h m u R$ gene (complementary to bp 18-43) contained a 10 bp inverted repeat (Fig. 3a). Secondary structure analysis and computations of that region using Mfold (Zuker, 2003) have shown that the sequence has the potential to form a stem-loop structure with predicted stability equivalent to free energy of dissociation of $-16.9 \mathrm{kcal} \mathrm{mol}^{-1} \quad\left(-70.7 \mathrm{~kJ} \mathrm{~mol}^{-1}\right)$ (Fig. 3a). A second inverted repeat capable of forming a less stable structure $\left(-7 \cdot 7 \mathrm{kcal} \mathrm{mol}^{-1} ;-32 \cdot 2 \mathrm{~kJ} \mathrm{~mol}^{-1}\right)$ was detected adjacent to it (bp 80-98) (not shown in Fig. 3a). A third repeat capable of forming an equally stable stem-loop structure $\left(-17.8 \mathrm{kcal} \mathrm{mol}^{-1} ;-74.5 \mathrm{~kJ} \mathrm{~mol}^{-1}\right)$ was detected in the middle of the $h m u R$ coding region (bp 899-934) (Fig. 3a). Finally, a fourth 13 bp inverted repeat was detected within $5^{\prime}$ coding region of the $h m u S$ gene (bp 24-54). The computed stability of this region was $-20 \cdot 8 \mathrm{kcal} \mathrm{mol}^{-1}\left(-87 \cdot 0 \mathrm{~kJ} \mathrm{~mol}^{-1}\right)$ (Fig. 3a). The presence of the stem-loop structures within the $h m u$ locus suggests that differential expression may take place within the locus.

\section{Genes within the hmu locus are co-transcribed}

There are six genes within the $h m u$ locus encoding potential haemin-acquisition proteins (Fig. 3a). The structure of the locus indicates that genes within the locus are co-transcribed and suggests the presence of a transcript approximately $9 \mathrm{~kb}$ in size that would be expected in the absence of differentially abundant messages. The first approach we used to detect an $h m u$-specific transcript was Northern blot analysis. To test the iron-dependent transcription of the $h m u$ locus, we performed analyses on total RNA isolated from $P$. gingivalis W83 grown in iron-replete and iron-chelated conditions. We detected $h m u Y$ - and $h m u R$-specific transcripts that were more abundant in iron-chelated conditions (Fig. 3b). However, no hybridization signals were obtained using 
probes specific for the $h m u S, h m u T, h m u U$ and $h m u V$ genes with RNA from bacteria grown either in iron-replete or in iron-depleted conditions (data not shown).

The Northern blot analysis verified the co-transcription within the $h m u Y R$ sublocus. Unexpectedly we also detected a $1 \mathrm{~kb}$ transcript specific for $h m u Y$. These data suggest that differential expression takes place within the operon and that $h m u Y$ mRNA is more prevalent than the $h m u Y R$ mRNA. The absence of the expected $9 \mathrm{~kb}$ transcript also indicated limitations of the Northern blot technique in detecting sparse messages that may be contiguous with upstream more abundant transcripts.

Since we were not able to detect messages for all genes within the locus, we performed a more sensitive assay: RT-PCR. The locations of primers used in this study are shown in Fig. 3(a); sequences of the primers are available as supplementary data (Table S1). The results are shown in Fig. 3(c). To confirm the co-transcription of the $h m u Y R$ locus, we performed RT-PCR using primers 1619 and 263. The PCR product of expected size confirmed the cotranscription of the two genes (Fig. 3c, lane 3). To test the co-transcription of $h m u R$ with $h m u S$ we used primers 267 and 265. Again, the PCR product of expected size was detected (Fig. 3c, lane 7). The co-transcription of hmuST was established by observation of an expected $1 \cdot 1 \mathrm{~kb}$ PCR product using primers 266 and 288 (Fig. 3c, lane 11). Lastly, the co-transcription of hmuTUV was demonstrated by a $1 \mathrm{~kb}$ PCR product obtained using primers 270 and 269 (Fig. 3c, lane 16). Interestingly, the PCR products through the $h m u Y R$ and through the $h m u R S$ regions were obtained only when cDNA synthesized at a higher temperature $\left(60{ }^{\circ} \mathrm{C}\right.$ vs $42{ }^{\circ} \mathrm{C}$ ) was used as a template (Fig. $2 \mathrm{c}$, lanes 3 and 7 ).

To further examine the operonic organization and the possibility of the presence of internal promoters we constructed the isogenic mutant V2794, containing a deletion of most of the first gene of the locus, hmuY. Since the antibiotic-resistance cassette used in this study (Fletcher et al., 1995) contains a transcriptional terminator, this lesion would be expected to have a polar effect if the genes within the locus are co-transcribed. Thus, we quantified the transcript level for all genes present in the locus using total RNA isolated from the parental and mutant strains by realtime RT-PCR. While messages for all genes were present in the parental strain, the $h m u$-specific messages were barely detectable in the mutant strain (results not shown), indicating that the mutation has a polar effect on the genes downstream as well as further confirming RT-PCR data indicating that the genes within the locus are transcribed as a single unit. In addition, this experiment suggests that there is no internal promoter within the operon.

\section{The hmuY promoter is located 292 bp upstream of the translational start site}

$h m u Y$ is separated from an upstream gene $\operatorname{prtC}$ by an intergenic region of $855 \mathrm{bp}$. Although prtC is transcribed in the same orientation as $h m u Y$, it likely is not a part of the hmu operon. This is based on the size of the transcripts obtained from our Northern blot analysis, which are too short to contain prtC- and $h m u Y R$-specific transcripts. Thus, we searched for an $h m u Y$ promoter within the intergenic sequence. The location of the $h m u Y 5^{\prime}$ end mRNA was determined using 5' RACE (Fig. 4). Analysis of 5' RACE products from primary PCR revealed two bands with approximate sizes of $70 \mathrm{bp}$ and $290 \mathrm{bp}$ (Fig. 4a, lane 2). No amplification products were detected in reactions in which templates where reverse transcriptase was omitted during the cDNA synthesis step were used (Fig. 4a, lane 3). The secondary PCR produced two bands with approximate sizes of $180 \mathrm{bp}$ and $100 \mathrm{bp}$ (Fig. 4b, lane 2). No amplification product was obtained using the primary PCR from the negative control as a template (Fig. $4 \mathrm{~b}$, lane 3 ). Since the primers used for the secondary PCR analysis should result in a product smaller by approximately $100 \mathrm{bp}$ than that from the primary PCR the $180 \mathrm{bp}$ PCR product was of expected size. Thus, DNA from the gel slice containing the $180 \mathrm{bp}$ fragment was extracted and its sequence determined. Alignment of the sequence to a sequence upstream of $h m u Y$ demonstrated ligated product and thus presence of a transcriptional start site at $-292 \mathrm{bp}(\mathrm{G})$ upstream of the hmuY start site (Fig. 4c).

Analysis of sequence upstream of the transcriptional start site identified sequences similar to the typical E. coli RNA polymerase $\sigma^{70}$ consensus promoter sequences: centred at -35 , TTGACA, and at -10 , TATAAT, relative to the transcription initiation site (Hawley \& McClure, 1983) (Fig. 4c). Interestingly, we also located a 24 bp sequence capable of forming an inverted repeat structure that was positioned $148 \mathrm{bp}$ upstream of the transcriptional start site (Fig. 4c). Lastly, we found a putative ribosome-binding site with the sequence AAGGT located $9 \mathrm{bp}$ upstream of the translational initiation codon, ATG (Fig. 4c).

\section{Genes within the $h m u$ operon are iron repressed}

In view of the contradictory reports regarding the effect of iron and haemin on expression of the $h m u Y$ and $h m u R$ genes (Karunakaran et al., 1997; Simpson et al., 2000), we examined the effect of iron, haemin, haemoglobin and PPIX on expression of both those genes by real-time RTPCR. Data from 60 min incubation are shown in Table 2. A 31 -fold reduction of $h m u Y$-specific transcript was observed after addition of ferric chloride, and a 35 -fold reduction of the $h m u R$-specific transcript was noted. Similar results were observed after longer times of incubation (up to $24 \mathrm{~h}$; results not shown). Thus, we conclude that the hmu locus is repressed by iron.

Interestingly, a slight increase in both transcript levels was observed after addition of haemin and haemoglobin at 60 min of incubation (Table 2). No major changes in transcript levels were noted after addition of PPIX to the 
Table 2. Effect of iron and haemin on hmuY and hmuR expression

Haemin-depleted bacteria were inoculated into Mycoplasma broth supplemented with $10 \mu \mathrm{M}$ DP and various iron/haemin sources. Relative transcript abundance was determined using $20 \mathrm{ng}$ total RNA isolated from $P$. gingivalis W83 grown in various conditions. Data are means \pm SD of assays performed in triplicate. Calibration curve plots were generated using serial fivefold dilutions of $100 \mathrm{ng}$ total RNA as template. The numbers in parentheses show the results expressed relative to the control, which was set to 1 after normalization against $16 \mathrm{~S}$ rRNA.

\begin{tabular}{|lccccc|}
\hline \multirow{2}{*}{ Transcript } & \multicolumn{3}{c|}{ Relative transcript abundance } \\
\cline { 2 - 6 } & Control $(-\mathrm{Fe})$ & $\mathrm{FeCl}_{3}$ & Haemin & Haemoglobin \\
\hline hmuY & $96 \cdot 6 \pm 3 \cdot 33(1) \ddagger$ & $3 \cdot 1 \pm 0 \cdot 98(0 \cdot 032)$ & $129 \cdot 3 \pm 3 \cdot 68(1 \cdot 3)$ & $105 \cdot 6 \pm 5 \cdot 46(1 \cdot 1)$ & PPIX \\
$h m u R$ & $17 \cdot 6 \pm 2 \cdot 43(1)$ & $0 \cdot 5 \pm 0 \cdot 04(0 \cdot 028)$ & $29 \cdot 1 \pm 4 \cdot 04(1 \cdot 7)$ & $24 \cdot 3 \pm 2 \cdot 87(1 \cdot 4)$ & $19 \cdot 1 \pm 1 \cdot 61(1 \cdot 1)$ \\
\hline
\end{tabular}

haemin-starved cells, indicating that the increased gene expression was haemin-specific (Table 2).

\section{Genes within the $h m u$ operon are differentially expressed}

Our Northern blot analysis indicated differential expression within the operon. Thus we determined the amount of transcript for each gene of the $h m u$ operon in the presence and absence of added iron by real-time RT-PCR. Several levels of differential expression were noted (Table 3). First, the genes encoding the outer-membrane proteins were overexpressed when compared to the full-length transcript. The $h m u Y R$ mRNA was expressed at approximately $25-$ to 50 -fold higher level than the full-length transcript (Table 3). The overexpression of $h m u Y R$ transcript was observed using RNA from cells grown with and without iron (generated by addition of DP). Second, the hmuYRSTU-specific transcript was 20 - to 30 -fold more prevalent than the full-length transcript hmuYRSTUV (Table 3). Lastly, differential expression within the $h m u Y R$ suboperon encoding the outer-membrane proteins was observed. The expression of $h m u Y$-specific transcript was approximately 7 - to 20 -fold higher than the $h m u R$ mRNA (Table 3). Similar results were obtained using in vitro-synthesized $h m u Y$ - and $h m u R$ specific transcripts for the generation of calibration curves (see Table S2, available as supplementary data with the online version of this paper).

\section{HmuY is a multimeric haemin-binding protein}

We propose that HmuY and HmuR function together as a two-component haemin receptor. The haemin-binding ability of the TonB-dependent protein HmuR has already been demonstrated (Liu et al., 2006; Olczak et al., 2001). Thus we examined the ability of HmuY to bind haemin. For these studies recombinant $\mathrm{HmuY}$ protein was used. This protein was purified to homogeneity (Fig. 5a) and then incubated with haemin (Fig. 5b, c). We noted that HmuY heated and resolved under denaturing conditions forms monomers (Fig. 5a). However, when not heated and run under native conditions this protein formed oligomers in addition to the monomeric form (Fig. 5b). Notably, the various forms of $\mathrm{HmuY}$ bound haemin (Fig. 5c, lane 2). In our assays haemin also bound to BSA; however, no haeminbinding activity was detected using trypsin, indicating that the haemin binding to HmuY was specific (Fig. 5c, lanes 4 and 5).

\section{HmuYRSTUV is a haemin transporter}

To further define the contribution of the $h m u$ locus to haemin acquisition in $P$. gingivalis we examined wild-type and $h m u$-deficient mutant strains for binding and uptake of radiolabelled haemin. To determine the significance of the iron upregulation of the locus we used cells from irondepleted and iron-replete conditions. Haemin binding and uptake were measured after a $20 \mathrm{~min}$ incubation period.

\section{Table 3. $h m u$ transcript levels}

Twenty nanograms of total RNA isolated from $P$. gingivalis W83 grown in mBHI in iron-chelated $(-\mathrm{Fe})$ and iron-replete $(+\mathrm{Fe})$ conditions was used for these studies. Amplification rates are expressed as pg gene-specific transcript. Data are means \pm SD of assays performed in triplicate. Calibration curve plots were generated using serial fivefold dilutions of $0.02 \mathrm{pg}$ gene-specific DNA template. Ratios of $h m u$ gene specific transcripts expressed relative to the least abundant transcript $(h m u V$, which is set as 1$)$ are shown in parentheses.

\begin{tabular}{|c|c|c|c|c|c|c|}
\hline \multicolumn{7}{|c|}{ Transcript quantity } \\
\hline $\begin{array}{l}-\mathrm{Fe} \\
+\mathrm{Fe}\end{array}$ & $\begin{array}{l}10 \cdot 8 \pm 0 \cdot 8\left(5 \cdot 4 \times 10^{4}\right) \\
\text { e } 0 \cdot 7 \pm 0 \cdot 07\left(10^{4}\right)\end{array}$ & $\begin{array}{l}0 \cdot 26 \pm 0 \cdot 01\left(1 \cdot 3 \times 10^{2}\right) \\
0 \cdot 05 \pm 0 \cdot 01\left(7 \times 10^{2}\right)\end{array}$ & $\begin{array}{l}0.005 \pm 0.0003 \\
0.002 \pm 0.0003\end{array}$ & $\begin{array}{l}0 \cdot 003 \pm 0 \cdot 00005 \\
0 \cdot 0012 \pm 0 \cdot 00004\end{array}$ & $\begin{array}{r}0 \cdot 004 \pm 0 \cdot 0008 \text { (20) } \\
\text { 7) } 0 \cdot 0012 \pm 0 \cdot 0004 \text { (17) }\end{array}$ & $\begin{array}{c}0 \cdot 0002 \pm 0 \cdot 00001(1) \\
0 \cdot 00007 \pm 0 \cdot 0000006(1)\end{array}$ \\
\hline
\end{tabular}



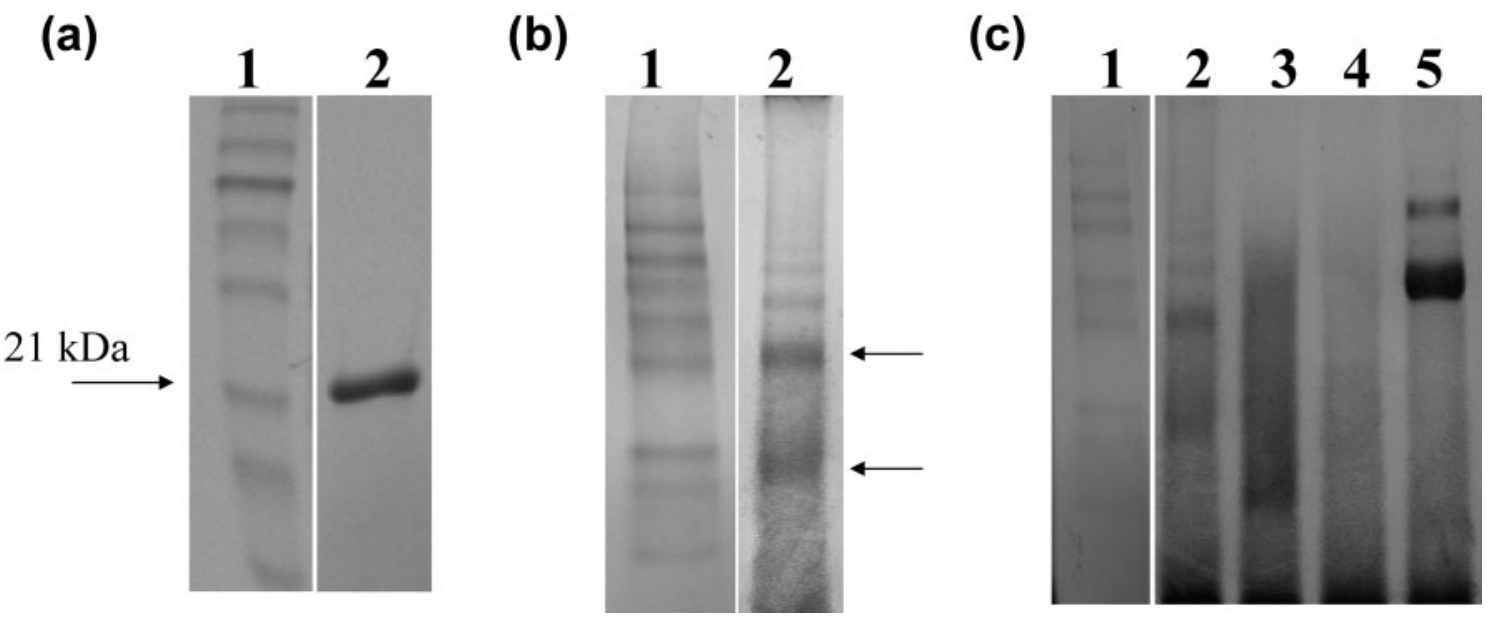

Fig. 5. Characterization of recombinant HmuY. (a) Denaturing gel: molecular mass markers (lane 1), $5 \mu \mathrm{g}$ purified recombinant HmuY mixed with Laemmli buffer, boiled and resolved on denaturing SDS-PAGE gel (lane 2). (b) Native gel: molecular mass markers (lane 1), $5 \mu \mathrm{g}$ purified recombinant $\mathrm{HmuY}$ (lane 2). Monomeric and dimeric forms of $\mathrm{HmuY}$ are indicated by arrows. (c) Native gel - haemin binding: $5 \mu \mathrm{g}$ recombinant HmuY (lane 2), $5 \mu \mathrm{g}$ trypsin (lane 4) and $5 \mu \mathrm{g}$ BSA (lane 5) were preincubated with haemin, resolved by LDS-PAGE and visualized with 4-methoxy-1-naphthol in the presence of $\mathrm{H}_{2} \mathrm{O}_{2}$ (lane 2). Bovine haemoglobin $(5 \mu \mathrm{g})$ is included in lane 3.

Haemin binding was determined using cells that were incubated on ice. Inhibition of $\left[{ }^{55} \mathrm{Fe}\right]$ haemin binding in the presence of equal amounts of unlabelled haemin demonstrated that the binding examined in this study was specific (results not shown). As shown in Fig. 6(a), significant haemin binding occurred in iron-replete conditions; however, no significant difference in the amount of bound haemin between the parental and hmu-deficient strains could be detected, indicating that this binding was not dependent on the HmuYR receptor and confirming the presence of other haemin-binding components in $P$. gingivalis. It is noteworthy that in iron-depleted conditions the amount of bound haemin detected in the parental strain was twofold elevated compared to that observed in the parental strain grown under iron-replete conditions and to that detected in the mutant strain, indicating that the HmuYR receptor plays a role in haemin binding (Fig. 6a). Also, the observation that the parental strain accumulated more haemin in iron-depleted conditions is consistent with the upregulation of the locus in those conditions.

We next examined the contribution of the locus to haemin uptake. As shown in Fig. 6(b) the haemin taken up by the parental strain grown in iron-depleted conditions was fourfold higher than that detected in the strain grown in iron-replete conditions. Furthermore, the haemin uptake in iron-depleted conditions was also approximately fourfold reduced in the mutant strain compared to the parental strain. No haemin uptake by the mutant strain was detected in iron-replete conditions. The inhibition of $\left[{ }^{55} \mathrm{Fe}\right]$ haemin uptake in the presence of equal amounts of unlabelled haemin demonstrated that the uptake examined in this study was specific (results not shown). These data indicate that the $h m u$ locus plays a role in haemin uptake and also are consistent with the upregulation of the locus in iron-depleted conditions.

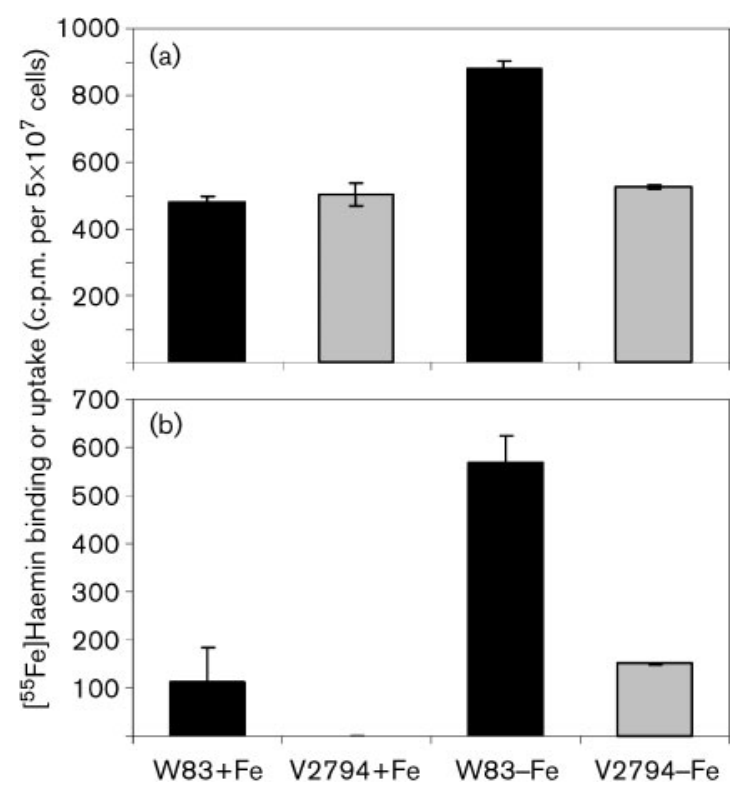

Fig. 6. Haemin binding and uptake. Binding (a) and uptake (b) of $\left[{ }^{55} \mathrm{Fe}\right]$ haemin binding were examined in $P$. gingivalis strains grown in iron-depleted $(-\mathrm{Fe})$ and iron-replete $(+\mathrm{Fe})$ conditions. ${ }^{55} \mathrm{Fe}$ binding or uptake was measured as c.p.m. per $5 \times 10^{7}$ cells after $20 \mathrm{~min}$ incubation on ice. 


\section{DISCUSSION}

We demonstrate here that the HmuY protein is a major iron-repressed outer-membrane protein. It is larger than previously reported and is encoded by a genomic locus comprising six putative haemin-acquisition genes. The gene products of the hmuSTUV portion of the locus are novel when compared to the typical bacterial haemin-acquisition systems. It is probable that while the outer-membrane proteins, HmuY and HmuR, would function as an outermembrane haemin receptor [analogously to the TbpBA transferrin receptor (Cornelissen, 2003)] the HmuSTUV proteins may be involved in processing and transport of the haemin molecule across the inner membrane. However, this functional assignment will need to be experimentally verified.

Although several multigenic loci encoding haemin-uptake proteins are present in $P$. gingivalis, not much is known regarding the transcriptional organization and expression within the loci. Such knowledge has implications when examining the operonic organization of the loci using Northern blot analysis and is also important when constructing mutant strains using antibiotic-resistance cassettes whose insertion results in termination of the transcript. Also, it may give an insight into the stoichiometry of the products encoded by the operon. The genetic structure of the $h m u$ locus suggested that the genes within the locus are co-transcribed. Our studies demonstrate that indeed the genes within the $h m u$ locus are transcribed as a single unit, and in agreement with that, insertion of the erm cassette containing a transcriptional terminator (Fletcher et al., 1995) into the first gene of the locus results in abrogation of all of the $h m u$ transcripts located downstream of the insertion.

To gain a better understanding of the mechanism underlying regulation of the $h m u$ operon, we examined the effect of various iron and haemin sources on expression of genes within the locus. We showed that expression of the genes is drastically elevated in iron-limited conditions. These data are in agreement with results reported by Simpson et al. (2000). However, no significant alterations in expression of $h m u Y R$ were observed when haemin was added to irondepleted cultures. These data contradict findings of Liu et al. (2004) and Karunakaran et al. (1997), who reported that $h m u R$ is down-regulated by haemin. Karunakaran et al. (1997) also reported that a variant of $h m u Y$, orfl, was upregulated in the presence of haemin, whereas we show that $h m u Y$ is regulated in the same fashion as $h m u R$, which is consistent with the operonic structure of the locus. The difference between our data and those of Karunakaran et al. (1997) may result from a nucleotide sequence difference between the strains used for the studies. Analysis of sequence upstream of orf1 (Karunakaran et al., 1997) revealed a 1 bp insertion (cytidine) located after bp 105 of the $h m u Y$ sequence reported in this study (Fig. S1). That change would result in a frame-shift and thus a different gene product. However, since our sequencing data demonstrate the presence of the $h m u Y$ variant from $P$. gingivalis W83 in most $P$. gingivalis strains, we expect that our findings regarding the length and regulation of the gene can also be applied to the majority of $P$. gingivalis strains.

The different results regarding the effects of haemin on regulation of the locus might be due to the inclusion of DP (in low concentrations) in our assays. Our studies were done in Mycoplasma broth containing low levels of iron and thus the $10 \mu \mathrm{M}$ DP that we used was sufficient to chelate the free iron present in the medium, as demonstrated by previous work (Bramanti \& Holt, 1991; Dashper et al., 2004). In addition, previous studies demonstrated haemin-dependent regulation. It is probable that the regulation was mediated by iron that was released from haemin, and thus DP was included in our study to chelate any haemin-derived iron so as to examine the effect of haemin alone on expression of the locus as opposed to haemin and iron.

Our data unequivocally show iron-dependent repression of the hmu locus. The most common regulator of irondependent expression in bacteria is Fur (Andrews et al., 2003; McHugh et al., 2003). A fur homologue has been identified in P. gingivalis (GenBank accession no. AF171224; TIGR annotation PG0456) (Nelson et al., 2003; Olczak et al., 2005). Initial studies in Genco's laboratory have shown that $P$. gingivalis Fur can partially complement the functional activity of the E. coli Fur (Liu et al., 2006). Thus we analysed the sequence upstream of the $h m u Y$ transcriptional start site for a consensus Fur-binding site. However, no such sequences were identified. It is possible that the sequences recognized by $P$. gingivalis Fur differ from the consensus Fur box sequences. The absence of E. coli-like Fur-binding consensus sequences has been observed in other bacteria (Friedman \& O'Brian, 2003; Palyada et al., 2004). It is also possible that the genes are regulated by a different mechanism (indirectly by Fur or independently of Fur). Another putative iron-dependent repressor is also encoded on the genome of $P$. gingivalis (PG1044). Finally, we identified an inverted repeat capable of forming secondary structure upstream of the transcriptional start site that may have a regulatory function.

The role of iron in regulation of haemin-uptake systems is well established; however, the transcript levels of individual genes within the multigenic transcription units encoding the components of the uptake systems remain largely unknown. Thus, it is noteworthy that we observed differential expression within the $h m u$ locus, resulting in higher levels of transcript for promoter-proximal genes than for promoter-distal genes. Since gene expression often correlates with protein expression in bacteria we can hypothesize that the transcript ratio also extends to the ratio of proteins encoded by the locus. The larger amount of HmuY compared with other proteins encoded by the locus would thus explain our observation of only one protein (HmuY) detected to be drastically upregulated on our SDSPAGE gel despite the fact that all genes within the locus are upregulated in the absence of iron. Explanations for the 
observed differences in gene expression within the hmuYRSTUV operon include differential transcript expression or stability. There is a precedent for differential expression within bacterial operons and usually it is a consequence of secondary structures (stem-loop structures) located within mRNA (Ehrmann et al., 1998; Khun et al., 2000; Newbury et al., 1987a, b; Ronpirin et al., 2001). Sequences capable of adopting the secondary structures are usually located in the intercistronic regions between the coding regions of genes within the operon. Interestingly, we identified inverted repeats with the potential to form stable stem-loop structures within the coding regions of the $h m u R$ and $h m u S$ genes. The first stem-loop (in the $5^{\prime}$ end of $h m u R$ ) may account for the termination of transcription after $h m u Y$, thus resulting in the $1 \mathrm{~kb}$ transcript (if the transcriptional start site was located approximately $400 \mathrm{bp}$ upstream of the locus). Repeat sequences capable of forming a secondary structure with a slightly higher calculated energy of dissociation $\left(-20 \cdot 8 \mathrm{kcal} \mathrm{mol}^{-1} ;-87 \cdot 0 \mathrm{~kJ} \mathrm{~mol}^{-1}\right)$ are located in the $5^{\prime}$ end of the hmuS coding region. The predicted stability of this structure is similar to that of one observed in another differentially regulated operon, the fbpABC locus of Neisseria meningitidis (Khun et al., 2000). The fact that the size of $h m u Y$ (with upstream sequences) is $1 \mathrm{~kb}$ and that of the $h m u R$ gene is $1.9 \mathrm{~kb}$ would be consistent with the $3 \mathrm{~kb}$ transcript corresponding to $h m u Y R$ detected in our Northern blot analysis. We also detected a putative stem-loop structure in the middle of the $h m u R$ transcript (bp 899-934). The location of this putative secondary structure could explain the presence of the $2 \mathrm{~kb}$ transcript in our Northern blot analysis. The higher temperatures needed for the cDNA synthesis through regions containing the sequences capable of forming the stem-loops imply that the secondary structures indeed form in the analysed RNA. However, further studies are required to definitely establish the role of the structures in the differences in transcript abundance observed within the hmu locus.

The differential expression within the $h m u$ operon may have functional implications. We have shown that there is excess of $h m u Y R$-specific message compared to the full-length hmuYRSTUV mRNA. HmuY and HmuR are outermembrane proteins and as such would serve as haemin receptors. HmuY is a novel protein with no significant similarity to other characterized proteins. However, three peptides derived from a $P$. gingivalis 381 cell envelope haemin-binding protein identified by Kim et al. (1996) show $90 \%, 90 \%$ and $89 \%$ identity, respectively, to internal regions of the protein characterized in this study, suggesting that these are the same proteins. Also, we have shown that $\mathrm{HmuY}$ binds haemin, and the haemin-binding property of HmuR has been demonstrated previously (Liu et al., 2006; Olczak et al., 2001). In agreement with the haemin-binding ability of the proteins we observed reduced haemin binding in the mutant devoid of the receptor. Also we show that the $h m u$ locus is a major haemin transporter in $P$. gingivalis. Since haemin is not freely available within the human host, capture of this nutrient at the bacterial cell surface would be a rate-limiting step. Also, an increased concentration of haemin receptors would be beneficial to efficiently compete for haemin binding with host haemin-scavenging proteins such as haemopexin and haemoglobin. Our data demonstrate that in iron-depleted conditions shown to elevate expression of the $h m u Y R$ receptor, drastic elevation of haemin uptake also occurred, thus suggesting that the rate of haemin uptake may be dependent on the concentration of the haemin receptors. Once in the cell, the haemin may be transported across the inner membrane using fewer transporters, hence the need for attenuation of the messages encoding the proteins. As observed in other bacterial transport systems (Mademidis \& Koster, 1998), the predicted preservation of the protein stoichiometry within the haemin-uptake locus might be crucial for efficiency of the haemin-transport process.

Since $P$. gingivalis requires haemin for generation of metabolic energy (Baughn \& Malamy, 2003; Schifferle et al., 1996; Takahashi et al., 2000), the mechanisms required for acquisition of the nutrient are expected to play a major role in establishment and growth of the bacteria in the human host. In that context, the prevalence of the $h m u$ locus in $P$. gingivalis as well as in other bacteria that require exogenous haemin for growth may reflect selective pressure to maintain this function. Interference with these mechanisms is expected to lead to growth arrest of the bacteria and as such can be exploited to design therapeutic measures. However, before one designs such therapeutics, it is critical to understand the structure, composition and regulation of the mechanisms of haemin uptake. The results presented here help clarify these issues.

\section{ACKNOWLEDGEMENTS}

These studies were supported from NIDCR K22DE14180 to J. P. Lewis. We thank Cynthia Nau Cornelissen and Todd Kitten for helpful discussions and critical reading of the manuscript. The real-time quantitative RT-PCR reactions and the synthesis of the probes were performed in the VCU Nucleic Acid Research Facilities. Sequence data for Porphyromonas gingivalis, Bacteroides fragilis, Bacteroides thetaiotaomicron and Prevotella intermedia were obtained from The Institute for Genomic Research website at http://www.tigr.org. Sequencing of $P$. gingivalis was accomplished with support from NIDCR.

\section{REFERENCES}

Aduse-Opoku, J., Slaney, J. M., Rangarajan, M., Muir, J., Young, K. A. \& Curtis, M. A. (1997). The Tla protein of Porphyromonas gingivalis W50: a homolog of the RI protease precursor (PrpRI) is an outer membrane receptor required for growth on low levels of hemin. J Bacteriol 179, 4778-4788.

Ahn, Y. J., Park, S. K., Oh, J. W., Sun, H. Y. \& Shin, S. H. (2004). Bacterial growth in amniotic fluid is dependent on the ironavailability and the activity of bacterial iron-uptake system. J Korean Med Sci 19, 333-340.

Andrews, S. C., Robinson, A. K. \& Rodriguez-Quinones, F. (2003). Bacterial iron homeostasis. FEMS Microbiol Rev 27, 215-237. 
Baughn, A. D. \& Malamy, M. H. (2003). The essential role of fumarate reductase in haem-dependent growth stimulation of Bacteroides fragilis. Microbiology 149, 1551-1558.

Beaven, G. H., Chen, S. H., d'Albis, A. \& Gratzer, W. B. (1974). A spectroscopic study of the haemin-human-serum-albumin system. Eur J Biochem 41, 539-546.

Bramanti, T. E. \& Holt, S. C. (1991). Roles of porphyrins and host iron transport proteins in regulation of growth of Porphyromonas gingivalis W50. J Bacteriol 173, 7330-7339.

Clarke, T. E., Tari, L. W. \& Vogel, H. J. (2001). Structural biology of bacterial iron uptake systems. Curr Top Med Chem 1, 7-30.

Cornelissen, C. N. (2003). Transferrin-iron uptake by gram-negative bacteria. Front Biosci 8, D836-D847.

Curtis, M. A., Kuramitsu, H. K., Lantz, M., Macrina, F. L., Nakayama, K., Potempa, J., Reynolds, E. C. \& Aduse-Opoku, J. (1999). Molecular genetics and nomenclature of proteases of Porphyromonas gingivalis. J. Periodont Res 34, 464-472.

Dashper, S. G., Hendtlass, A., Slakeski, N., Jackson, C., Cross, K. J., Brownfield, L., Hamilton, R., Barr, I. \& Reynolds, E. C. (2000). Characterization of a novel outer membrane hemin-binding protein of Porphyromonas gingivalis. J Bacteriol 182, 6456-6462.

Dashper, S. G., Cross, K. J., Slakeski, N., Lissel, P., Aulakh, P., Moore, C. \& Reynolds, E. C. (2004). Hemoglobin hydrolysis and heme acquisition by Porphyromonas gingivalis. Oral Microbiol Immunol 19, 50-56.

Ehrmann, M., Ehrle, R., Hofmann, E., Boos, W. \& Schlosser, A. (1998). The ABC maltose transporter. Mol Microbiol 29, 685-694.

Fletcher, H. M., Schenkein, H. A., Morgan, R. M., Bailey, K. A., Berry, C. R. \& Macrina, F. L. (1995). Virulence of a Porphyromonas gingivalis W83 mutant defective in the prtH gene. Infect Immun 63, 1521-1528.

Fox, C. H. (1992). New considerations in the prevalence of periodontal disease. Curr Opin Dent 2, 5-11.

Francis, R. T., Jr \& Becker, R. R. (1984). Specific indication of hemoproteins in polyacrylamide gels using a double-staining process. Anal Biochem 136, 509-514.

Friedman, Y. E. \& O'Brian, M. R. (2003). A novel DNA-binding site for the ferric uptake regulator (Fur) protein from Bradyrhizobium japonicum. J Biol Chem 278, 38395-38401.

Genco, C. A. \& Dixon, D. W. (2001). Emerging strategies in microbial haem capture. Mol Microbiol 39, 1-11.

Hawley, D. K. \& McClure, W. R. (1983). Compilation and analysis of Escherichia coli promoter DNA sequences. Nucleic Acids Res 11, 2237-2255.

Hrkal, Z., Vodrazka, Z. \& Kalousek, I. (1974). Transfer of heme from ferrihemoglobin and ferrihemoglobin isolated chains to hemopexin. Eur J Biochem 43, 73-78.

Hwang, P. K. \& Greer, J. (1980). Interaction between hemoglobin subunits in the hemoglobin-haptoglobin complex. J Biol Chem 255 , 3038-3041.

Karunakaran, T., Madden, T. \& Kuramitsu, H. (1997). Isolation and characterization of a hemin-regulated gene, hemR, from Porphyromonas gingivalis. J Bacteriol 179, 1898-1908.

Khun, H., Deved, V., Wong, H. \& Lee, B. C. (2000). The Neisseria meningitidis $f b p A B C$ locus is transcribed as an operon. Infect Immun 68, 7166-7171.

Kim, S. J., Chu, L. \& Holt, S. C. (1996). Isolation and characterization of a hemin-binding cell envelope protein from Porphyromonas gingivalis. Microb Pathog 21, 65-70.

Laemmli, U. K. (1970). Cleavage of structural proteins during the assembly of the head of bacteriophage T4. Nature 227, 680-685.

Lee, B. C. (1995). Quelling the red menace: haem capture by bacteria. Mol Microbiol 18, 383-390.
Lewis, J. P. \& Macrina, F. L. (1998). IS195, an insertion sequence-like element associated with protease genes in Porphyromonas gingivalis. Infect Immun 66, 3035-3042.

Lewis, J. P., Dawson, J. A., Hannis, J. C., Muddiman, D. \& Macrina, F. L. (1999). Hemoglobinase activity of the lysine gingipain protease (Kgp) of Porphyromonas gingivalis W83. J Bacteriol 181, 4905-4913.

Liu, X., Sroka, A., Potempa, J. \& Genco, C. A. (2004). Coordinate expression of the Porphyromonas gingivalis lysine-specific gingipain proteinase, Kgp, arginine-specific gingipain proteinase, RgpA, and the heme/hemoglobin receptor, HmuR. Biol Chem 385, 1049-1057.

Liu, X., Olczak, T., Guo, H. C., Dixon, D. W. \& Genco, C. A. (2006). Identification of amino acid residues involved in heme binding and hemoprotein utilization in the Porphyromonas gingivalis heme receptor HmuR. Infect Immun 74, 1222-1232.

Mademidis, A. \& Koster, W. (1998). Transport activity of FhuA, FhuC, FhuD, and FhuB derivatives in a system free of polar effects, and stoichiometry of components involved in ferrichrome uptake. Mol Gen Genet 258, 156-165.

McHugh, J. P., Rodriguez-Quinones, F., Abdul-Tehrani, H., Svistunenko, D. A., Poole, R. K., Cooper, C. E. \& Andrews, S. C. (2003). Global iron-dependent gene regulation in Escherichia coli. A new mechanism for iron homeostasis. J Biol Chem 278, 2947829486.

Nelson, K. E., Fleischmann, R. D., DeBoy, R. T. \& 20 other authors (2003). Complete genome sequence of the oral pathogenic bacterium Porphyromonas gingivalis strain W83. J Bacteriol 185, 5591-5601.

Newbury, S. F., Smith, N. H. \& Higgins, C. F. (1987a). Differential mRNA stability controls relative gene expression within a polycistronic operon. Cell 51, 1131-1143.

Newbury, S. F., Smith, N. H., Robinson, E. C., Hiles, I. D. \& Higgins, C. F. (1987b). Stabilization of translationally active mRNA by prokaryotic REP sequences. Cell 48, 297-310.

Ochsner, U. A., Johnson, Z. \& Vasil, M. L. (2000). Genetics and regulation of two distinct haem-uptake systems, phu and has, in Pseudomonas aeruginosa. Microbiology 146, 185-198.

Olczak, T., Dixon, D. W. \& Genco, C. A. (2001). Binding specificity of the Porphyromonas gingivalis heme and hemoglobin receptor $\mathrm{HmuR}$, gingipain $\mathrm{K}$, and gingipain $\mathrm{R} 1$ for heme, porphyrins, and metalloporphyrins. J Bacteriol 183, 5599-5608.

Olczak, T., Simpson, W., Liu, X. \& Genco, C. A. (2005). Iron and heme utilization in Porphyromonas gingivalis. FEMS Microbiol Rev 29, 119-144.

Palyada, K., Threadgill, D. \& Stintzi, A. (2004). Iron acquisition and regulation in Campylobacter jejuni. J Bacteriol 186, 4714-4729.

Panek, H. \& O'Brian, M. R. (2002). A whole genome view of prokaryotic haem biosynthesis. Microbiology 148, 2273-2282.

Rao, V. K., Krasan, G. P., Hendrixson, D. R., Dawid, S. \& St Geme, J. W., III (1999). Molecular determinants of the pathogenesis of disease due to non-typable Haemophilus influenzae. FEMS Microbiol Rev 23, 99-129.

Rishi, P., Woodward, C. L., Kim, W. K. \& Ricke, S. C. (2004). Salmonella enterica serovar Typhimurium hilA-lacZY fusion gene response to iron chelation or supplementation in rich and minimal media. J Environ Sci Health B 39, 861-870.

Ronpirin, C., Jerse, A. E. \& Cornelissen, C. N. (2001). Gonococcal genes encoding transferrin-binding proteins $\mathrm{A}$ and $\mathrm{B}$ are arranged in a bicistronic operon but are subject to differential expression. Infect Immun 69, 6336-6347.

Schifferle, R. E., Shostad, S. A., Bayers-Thering, M. T., Dyer, D. W. \& Neiders, M. E. (1996). Effect of protoporphyrin IX limitation on Porphyromonas gingivalis. J Endod 22, 352-355. 
Sexton, J. A., Pinkner, J. S., Roth, R., Heuser, J. E., Hultgren, S. J. \& Vogel, J. P. (2004). The Legionella pneumophila PilT homologue DotB exhibits ATPase activity that is critical for intracellular growth. $J$ Bacteriol 186, 1658-1666.

Simpson, W., Olczak, T. \& Genco, C. A. (2000). Characterization and expression of HmuR, a TonB-dependent hemoglobin receptor of Porphyromonas gingivalis. J Bacteriol 182, 5737-5748.

Slakeski, N., Dashper, S. G., Cook, P., Poon, C., Moore, C. \& Reynolds, E. C. (2000). A Porphyromonas gingivalis genetic locus encoding a heme transport system. Oral Microbiol Immunol 15, 388-392.

Slots, J., Bragd, L., Wikstrom, M. \& Dahlen, G. (1986). The occurrence of Actinobacillus actinomycetemcomitans, Bacteroides gingivalis and Bacteroides intermedius in destructive periodontal disease in adults. J Clin Periodontol 13, 570-577.

Stojiljkovic, I. \& Hantke, K. (1994). Transport of haemin across the cytoplasmic membrane through a haemin-specific periplasmic binding-protein-dependent transport system in Yersinia enterocolitica. Mol Microbiol 13, 719-732.

Takahashi, N., Sato, T. \& Yamada, T. (2000). Metabolic pathways for cytotoxic end product formation from glutamate- and aspartate-containing peptides by Porphyromonas gingivalis. $J$ Bacteriol 182, 4704-4710.

Thompson, J. M., Jones, H. A. \& Perry, R. D. (1999). Molecular characterization of the hemin uptake locus $(h m u)$ from Yersinia pestis and analysis of $h m u$ mutants for hemin and hemoprotein utilization. Infect Immun 67, 3879-3892.

Towbin, H., Staehelin, T. \& Gordon, J. (1992). Electrophoretic transfer of proteins from polyacrylamide gels to nitrocellulose sheets: procedure and some applications. Biotechnology 24, 145-149.

Vanderpool, C. K. \& Armstrong, S. K. (2001). The Bordetella bhu locus is required for heme iron utilization. J Bacteriol 183, 42784287.

Williams, G. D. \& Holt, S. C. (1985). Characteristics of the outer membrane of selected oral Bacteroides species. Can J Microbiol 31, 238-250.

Wyckoff, E. E., Duncan, D., Torres, A. G., Mills, M., Maase, K. \& Payne, S. M. (1998). Structure of the Shigella dysenteriae haem transport locus and its phylogenetic distribution in enteric bacteria. Mol Microbiol 28, 1139-1152.

Zuker, M. (2003). Mfold web server for nucleic acid folding and hybridization prediction. Nucleic Acids Res 31, 3406-3415. 